\title{
Induction of EMT-like phenotypes by an active metabolite of leflunomide and its contribution to pulmonary fibrosis
}

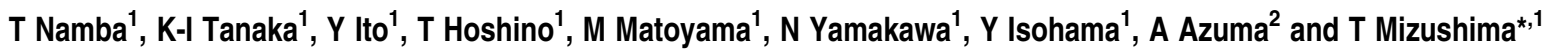

Drug-induced interstitial lung disease (ILD), particularly pulmonary fibrosis, is a serious clinical concern and myofibroblasts have been suggested to have a major role, with it recently being revealed that some of these myofibroblasts are derived from lung epithelial cells through epithelial-mesenchymal transition (EMT). In this study, we examined the EMT-inducing abilities of drugs known to induce ILD clinically. EMT-like phenotypes were induced by A771726, an active metabolite of leflunomide having an inhibitory effect on dihydroorotate dehydrogenase (DHODH). Smad-interacting protein 1 (a transcription factor regulating EMT) and the Notch-signaling pathway but not transforming growth factor- $\beta$ was shown to be involved in A771726-induced EMT-like phenotypes. When the cultures were supplemented with exogenous uridine, the A771726-induced EMT-like phenotypes and activation of the Notch-signaling pathway disappeared. Similarly, an A771726 analog without inhibitory activity on DHODH produced no induction, suggesting that this process is mediated through the inhibition of DHODH. In vivo, administration of leflunomide stimulated bleomycin-induced EMT-like phenomenon in pulmonary tissue, and exacerbated bleomycin-induced pulmonary fibrosis, both of which were suppressed by coadministration of uridine. Taken together, these findings suggest that leflunomide-dependent exacerbation of bleomycin-induced pulmonary fibrosis is mediated by stimulation of EMT of lung epithelial cells, providing the first evidence that drug-induced pulmonary fibrosis involves EMT of these cells.

Cell Death and Differentiation (2010) 17, 1882-1895; doi:10.1038/cdd.2010.64; published online 21 May 2010

Interstitial lung disease (ILD), in particular interstitial pneumonia associated with pulmonary fibrosis, is a devastating chronic lung condition with poor prognosis. Pulmonary fibrosis progresses insidiously and slowly, with acute exacerbation of interstitial pneumonia being a highly lethal clinical event. Furthermore, the mortality rate for pulmonary fibrosis is increasing. ${ }^{1,2}$ Although most cases of pulmonary fibrosis are idiopathic, some are due to drug side effects (drug-induced pulmonary fibrosis). For example, the antitumor drugs imatinib and gefitinib, as well as the antirheumatoid arthritis drugs leflunomide and methotrexate, are known to induce ILD (pulmonary fibrosis). This is cause for serious clinical concern, as it can lead to patient death, thereby restricting the therapeutic use of these drugs. ${ }^{3-5}$ Unfortunately, the etiology of drug-induced ILD (pulmonary fibrosis) is not yet understood and, as a result, an appropriate animal model has not yet been established. Although the bleomycin-induced pulmonary fibrosis animal model mimics some characteristics of human pulmonary fibrosis, ${ }^{6}$ it remains unclear whether drugs known to induce ILD clinically exacerbate bleomycin-induced effects. Therefore, understanding the mechanism governing drug-induced ILD (pulmonary fibrosis) and developing a viable animal model are important to establish not only a clinical protocol for its treatment but also an assay system that will facilitate screening to eliminate candidate drugs with the potential to produce this type of side effect.

It is now believed that pulmonary fibrosis is induced by repeated epithelial cell damage and abnormal wound repair and remodeling, resulting in abnormal deposition of extracellular matrix (ECM) proteins, such as collagen. Cytokines, in particular transforming growth factor (TGF)- $\beta_{1}$, have been reported to have an important role in pulmonary fibrosis. ${ }^{7}$ Inflammation, particularly that mediated by TGF- $\beta_{1}$ and reactive oxygen species is involved in repeated lung epithelial cell damage. ${ }^{8}$ On the other hand, an increase in lung myofibroblasts has been suggested to have an important role in abnormal wound repair and remodeling. ${ }^{9}$ Myofibroblasts extensively produce and secrete ECM proteins, ${ }^{9}$ and are involved in abnormal wound repair and remodeling through various mechanisms, including deregulation of the balance between matrix metallopeptidases (MMPs) and tissue inhibitors of MMPs (TIMPs). ${ }^{10}$ It was previously believed that the

${ }^{1}$ Graduate School of Medical and Pharmaceutical Sciences, Kumamoto University, Kumamoto 862-0973, Japan and ${ }^{2}$ Division of Respiratory, Department of Internal Medicine, Infection and Oncology, Nippon Medical School, Tokyo 113-8602, Japan

*Corresponding author: T Mizushima, Graduated School of Medical and Pharmaceutical Sciences, Kumamoto University, 5-1 Oe-honmachi, Kumamoto 862-0973, Japan. Tel/Fax: + 8196371 4323; E-mail: mizu@gpo.kumamoto-u.ac.jp

Keywords: EMT; leflunomide; pulmonary fibrosis

Abbreviations: 6-MP, 6-mercaptopurine; $\alpha$-SMA, $\alpha$-smooth muscle actin; BSA, bovine serum albumin; CTGF, connective tissue growth factor; DAPI, 4,6-diamino-2phenylindole; DAPT, $N$-[N-(3,5-difluorophenacetyl-L-alanyl)]-S-phenylglycine t-butyl ester; DHODH, dihydroorotate dehydrogenase; DMBA, 4-(dimethylamino)benzaldehyde; DII-1, Delta-like 1; ECM, extracellular matrix; EMT, epithelial-mesenchymal transition; FBS, fetal bovine serum; ILD, interstitial lung disease; MMP, matrix metallopeptidase; NICD, Notch intracellular domain; proSP-C, precursor of surfactant protein-C; ISIP-1, Smad-interacting protein 1; TIMP, tissue inhibitor of matrix metalloprotease; TGF, transforming growth factor

Received 07.12.09; revised 08.4.10; accepted 19.4.10; Edited by RA Knight; published online 21.5.10 
origin of myofibroblasts is solely peribronchiolar and perivascular fibroblasts that transdifferentiate to myofibroblasts in response to various stimuli, in particular TGF- $\beta_{1} .{ }^{11}$ However, recently, it was shown that lung epithelial cells undergo epithelial-mesenchymal transition (EMT) to become myofibroblasts after treatment with TGF- $\beta_{1}$ in vitro. ${ }^{12,13}$ The EMT of lung epithelial cells also seems to be induced in the lungs of pulmonary fibrosis patients and bleomycin-treated animals. ${ }^{12,14}$ Furthermore, inhibition of EMT by knockout of the integrin- $\alpha 3$ gene has been shown to suppress bleomycininduced pulmonary fibrosis in mice. ${ }^{15}$ These results suggest that some of the lung myofibroblasts in pulmonary fibrosis patients originate from lung epithelial cells through the EMT, and that EMT has an important role in the pathogenesis of the condition, including that induced by drugs. However, the involvement of EMT in drug-induced pulmonary fibrosis has not previously been examined.

Leflunomide, one of a number of newly developed diseasemodifying antirheumatic drugs, ${ }^{16,17}$ suppresses the cell-cycle progression of $T$ lymphocytes and other types of cells by inhibiting mitochondrial dihydroorotate dehydrogenase (DHODH), which is the fourth enzyme in the de novo synthesis of pyrimidine. ${ }^{18}$ This mechanism is supported by the observation that the inhibitory effect of leflunomide on cell growth is canceled by supplementing the cultures with exogenous uridine, which is a substrate of the salvage pathway of pyrimidine synthesis. ${ }^{18}$ Postmarketing surveillance for all patients prescribed with leflunomide in Japan showed that 80 of 5911 patients developed interstitial pneumonia and that of these, 27 died, with ILD being judged to be the primary cause of death in at least 18 cases. The incidence of leflunomide-induced ILD and its mortality rate are higher than the corresponding figures in Western countries; ${ }^{16,17,19,20}$ however, the mechanism governing this racial difference for susceptibility to drug-induced ILD is unknown.

In this study, we examined the EMT-inducing abilities of drugs known to cause ILD clinically. Our results showed that A771726, an active metabolite of leflunomide, induces EMTlike phenotypes in cultured human type II alveolar (A549) cells through the inhibition of $\mathrm{DHODH}$. We also provide evidence that administration of leflunomide stimulates bleomycininduced EMT-like phenomenon in the pulmonary tissue and exacerbates bleomycin-induced pulmonary fibrosis. On the basis of these findings, we consider that leflunomide-induced pulmonary fibrosis involves EMT of lung epithelial cells and that this leflunomide-dependent exacerbation of bleomycininduced pulmonary fibrosis provides a suitable animal model of drug-induced ILD.

\section{Results}

Induction of EMT-like phenotypes by an active metabolite of leflunomide in vitro. We first set out to examine the in vitro EMT-inducing abilities of drugs known, to induce ILD clinically. As one of the phenotypes related to EMT is growth inhibition, ${ }^{21}$ we initially determined the concentration of each drug (A771726 (an active metabolite of leflunomide), amiodarone, methotrexate, imatinib and gefitinib) that led to the suppression of A549 cell growth (Supplementary Figure S1a).
Upregulation of the expression of myofibroblast marker proteins (such as $\alpha$-smooth muscle actin ( $\alpha$-SMA) and collagen I) and downregulation of the expression of epithelial cell marker proteins (such as E-cadherin and precursor of surfactant protein C (proSP-C)) can be used to monitor EMT. Treatment of cells with $A 771726$ or methotrexate upregulated the expression of $\alpha$-sma and col1a1 (one of the genes for collagen I) mRNAs, and downregulated E-cadherin mRNA expression (Supplementary Figure S1b). The other drugs tested (amiodarone, imatinib and gefitinib) did not significantly affect the expression of these genes, except for the downregulation of E-cadherin mRNA expression by gefitinib (Supplementary Figure S1b). Immunoblotting analysis showed that protein expression of $\alpha$-SMA or proSP-C and E-cadherin was increased or decreased, respectively, in the presence of A771726 or methotrexate (Supplementary Figure S1c). As these results suggested that both $A 771726$ and methotrexate can induce EMT in A549 cells, we took into consideration the plasma concentrations of these two drugs at clinical doses (see discussion), before selecting A771726 for further experiments.

As shown in Figure 1a and $b$, the change in the expression of EMT-related genes (proteins) was dependent on the dose of A771726. Immunostaining analysis showed that treatment of A549 cells with A771726 reduced the expression of E-cadherin at the cell periphery and induced the expression of $\alpha$-SMA in the cytosol (Figure 1c). We also examined the effect of A771726 on EMT-like phenotypes in primary cultured rat alveolar epithelial cells. As shown in Figure $2 a-c$, A771726-dependent upregulation or downregulation of the expression of $\alpha$-SMA and collagen or E-cadherin and proSP-C, respectively, was also observed in primary cultured rat alveolar epithelial cells, although such alteration was observed with lower concentration of A771726 in primary cultured rat alveolar epithelial cells than in A549 cells.

We also examined the effect of A771726 on other EMTrelated phenotypes, including an increase in cell migration activity and the activity and expression of MMPs and TIMPs. As shown in Figure 1d, treatment of cells with A771726 stimulated the migration activity of A549 cells. The band intensity based on gelatin zymography, indicative of MMP-2 and MMP-9 activity, was also increased by treatment of cells with A771726 (Figure 1e). The level of TIMP-1 in the culture medium increased in the presence of $A 771726$ (Figure 1f) Furthermore, the expression of $m m p-2, m m p-9$ and timp-1 mRNAs was upregulated (Figure 1g). Taken together, these findings support the idea that A771726 induces EMT in A549 cells.

Involvement of Smad-interacting protein 1 and the Notch-signaling pathway in A771726-induced EMT-like phenotypes. A number of transcription factors (such as Snail, Twist, Smad-interacting protein 1 (SIP1) and Slug) are involved in the induction of EMT. ${ }^{22}$ As shown in Figure $3 a$, treatment of cells with A771726 upregulated mRNA expression of SIP1 and Slug and, to a lesser extent, Twist. A771726-dependent upregulation of expression of SIP1 and Slug was also observed at the protein level (Figure 3b). Thus, we tested the contribution of SIP1 to A771726-induced EMT-like phenotypes using its siRNA (unfortunately, we could not obtain siRNA that efficiently suppresses the 


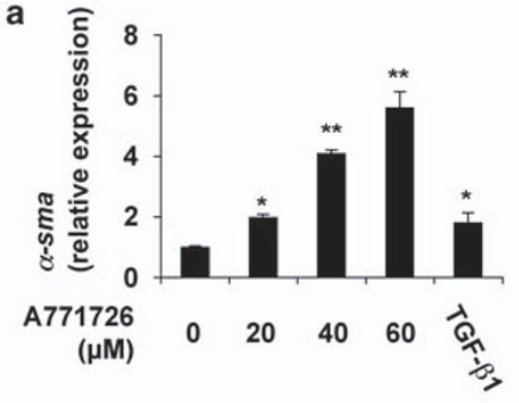

b

d

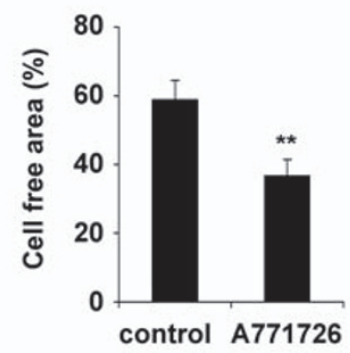

g

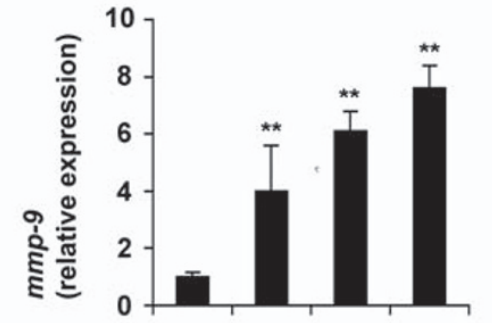

A771726

$(\mu \mathrm{M})$

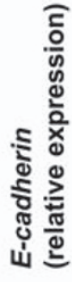

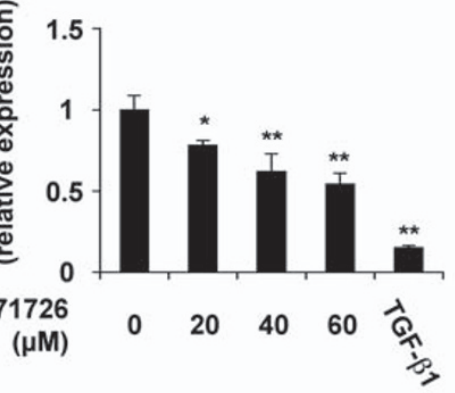

C
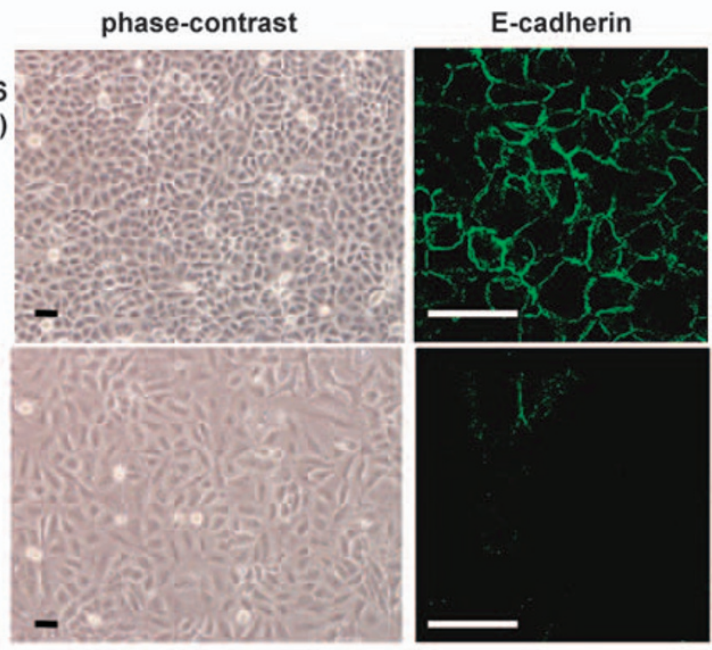

$\alpha$-SMA

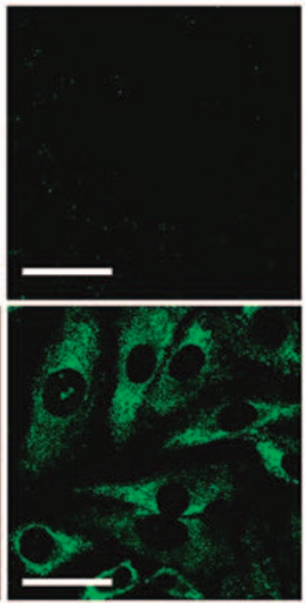

e
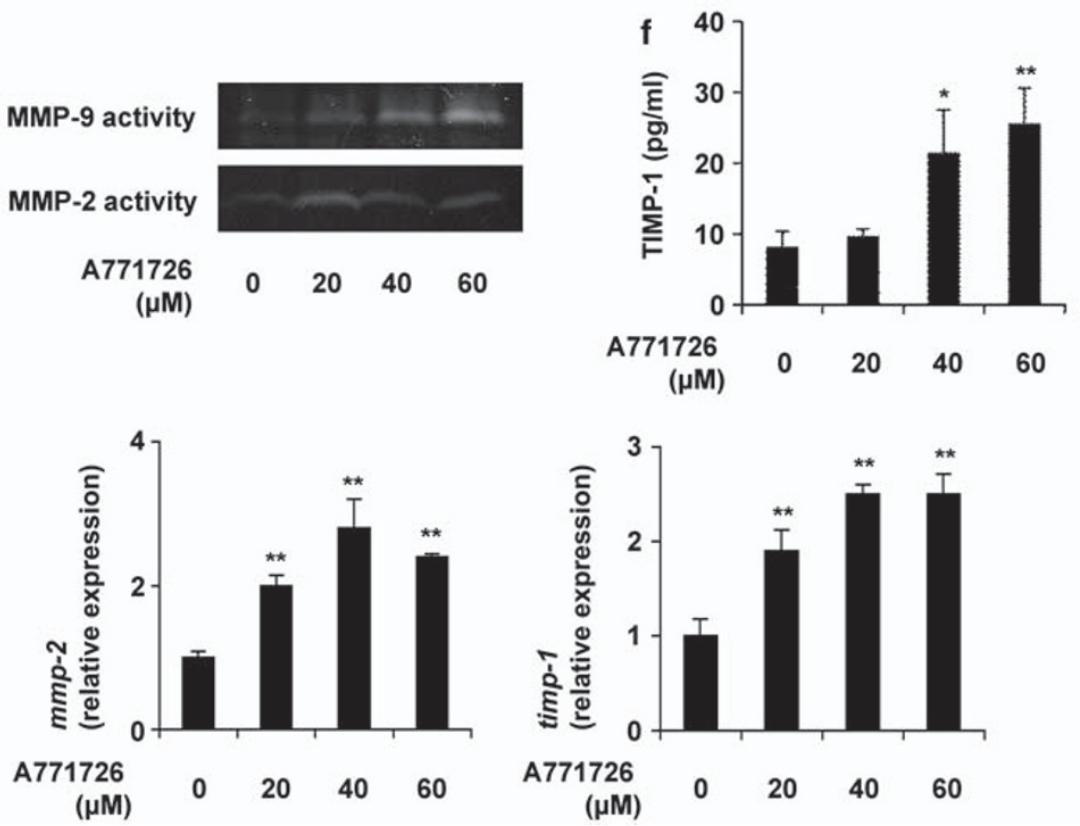

Figure 1 Induction of EMT-like phenotypes by A771726. A549 cells were incubated with the indicated concentration (a, b, e-g) or $40 \mu \mathrm{M}(\mathbf{c}, \mathbf{d})$ of A771726 or $1 \mathrm{ng} / \mathrm{ml}$ TGF- $\beta 1$ (panels a, b) for $48 \mathrm{~h}$ (panels a, g) or $96 \mathrm{~h}$ (panels b-f). (Panels a, g) Total RNA was extracted and subjected to real-time RT-PCR using a specific primer set for each gene. Values were normalized to the actin gene, expressed relative to the control sample. (Panel b) Whole-cell extracts were analyzed by immunoblotting with an antibody against $\alpha$-SMA, proSP-C, E-cadherin or actin. (Panel c) Morphological changes in the cells were examined by phase-contrast microscopic observation and immunostaining with an antibody against E-cadherin or $\alpha$-SMA (scale bar, $50 \mu \mathrm{m}$ ). (Panel d) After making wounds, the cells were incubated for $24 \mathrm{~h}$ without each drug. The cell-free area was measured and expressed relative to that before the incubation. (Panel e) MMP-9 and MMP-2 activity in the culture medium was measured as described in the 'Materials and Methods' section. (Panel f) The level of TIMP-1 in the culture medium was determined by ELISA. Values shown are mean \pm S.D. $(n=3) .{ }^{\star} P<0.05 ;{ }^{* *} P<0.01$ (panels a, d, f, g) 


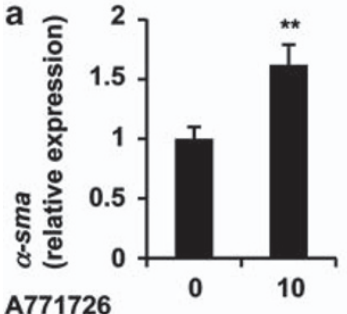

A771726

( $\mu \mathrm{M})$

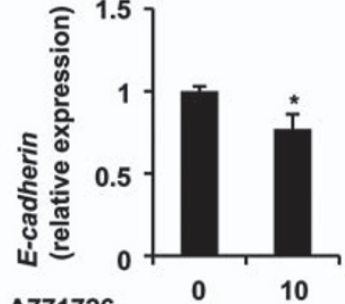

A771726

$(\mu \mathrm{M})$

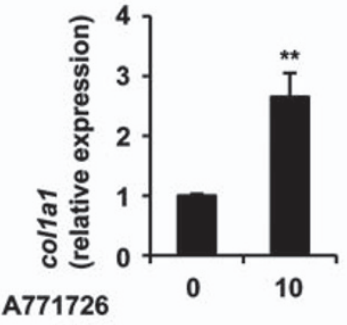

( $\mu \mathrm{M})$

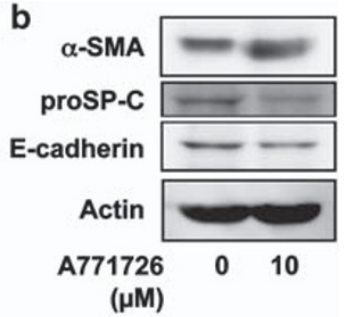

C $\mathbf{A 7 7 1 7 2 6}$

$(\mu \mathrm{M})$

10
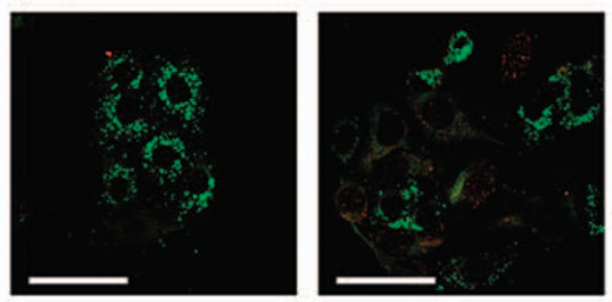

d

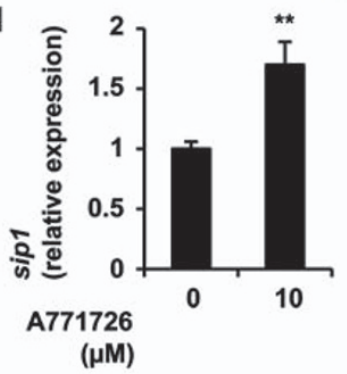

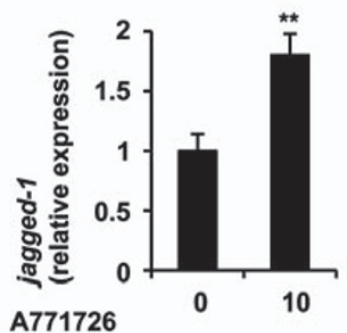

$(\mu \mathrm{M})$
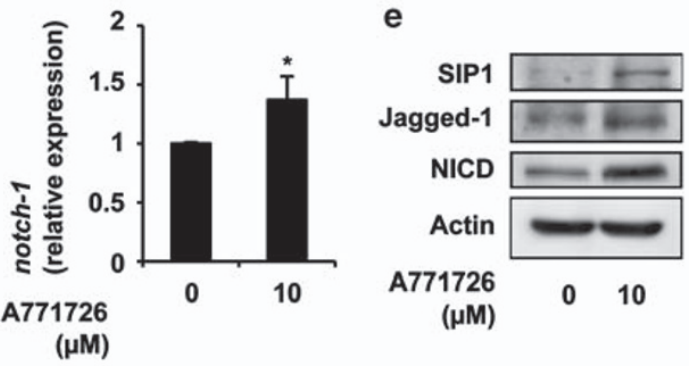

g
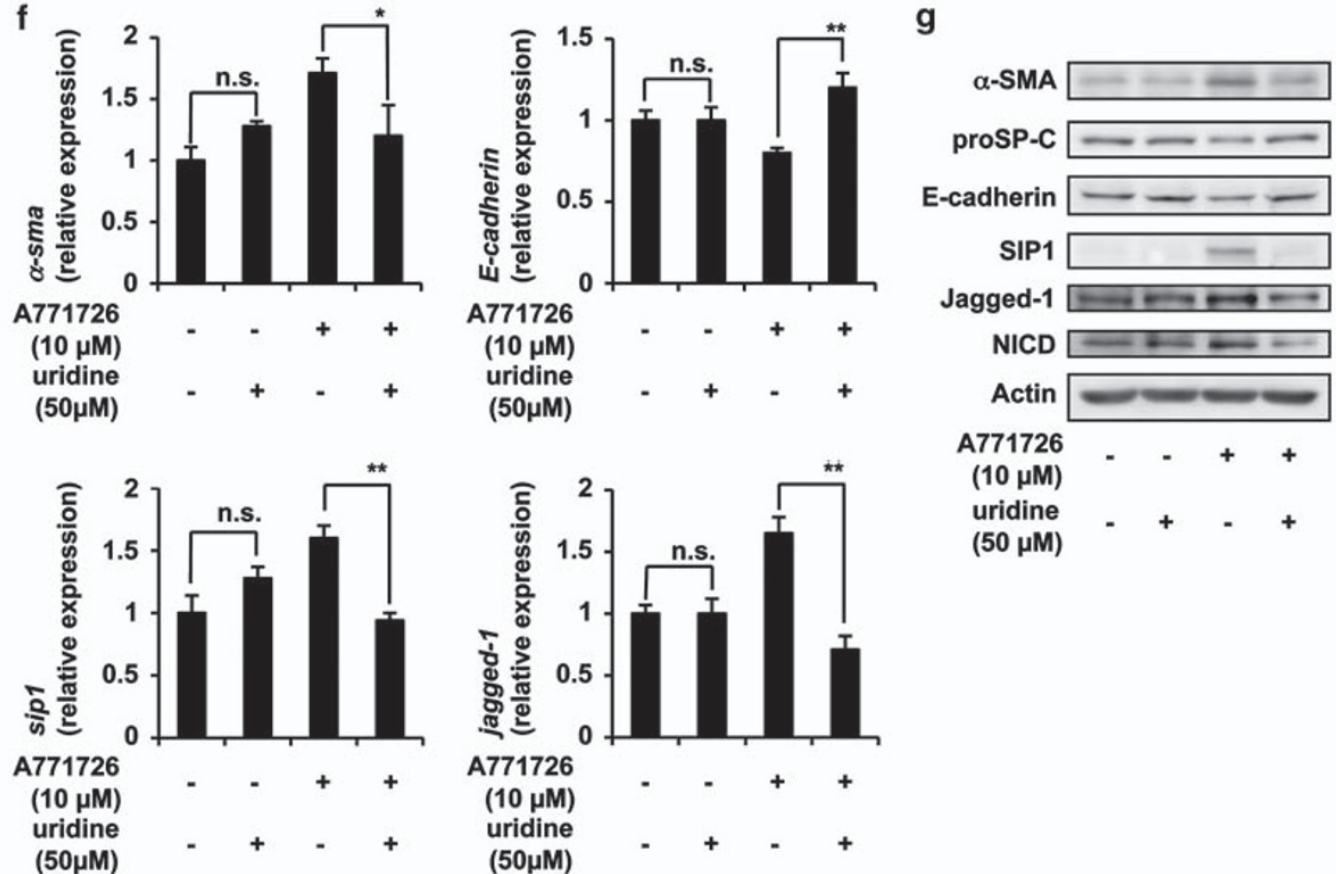

(50 $\mu \mathrm{M})$

Figure 2 Induction of EMT-like phenotypes by A771726 in primary cultured rat alveolar epithelial cells. Primary cultured rat alveolar epithelial cells were incubated with the indicated concentration of A771726 for $24 \mathrm{~h}$ in the absence $(\mathbf{a}-\mathbf{e})$ or presence $(\mathbf{f}, \mathbf{g})$ of $50 \mu \mathrm{M}$ uridine. (Panels $\mathrm{a}, \mathrm{b}, \mathrm{d}-\mathrm{g}) \mathrm{mRNA}$ and protein expression were monitored and expressed as described in the legend of Figure 1. (Panel c) Immunostaining with antibodies against $\alpha$-SMA (red) and proSP-C (green) (scale bar, $50 \mu \mathrm{m}$ ) was carried out as described in the 'Materials and Methods' section. Values shown are mean \pm S.D. $(n=3)$. ${ }^{\star} P<0.05 ;{ }^{\star \star} P<0.01$; n.s., not significant (panels a, $\left.d, f\right)$ 
a

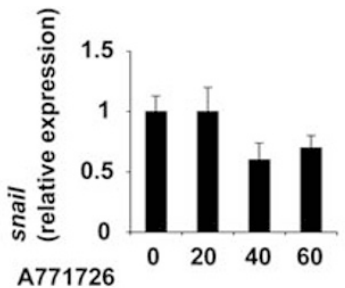

$(\mu \mathrm{M})$

b

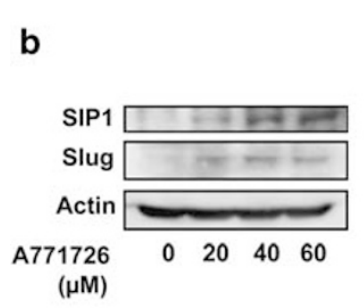

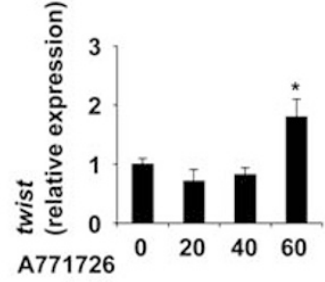

( $\mu \mathrm{M})$

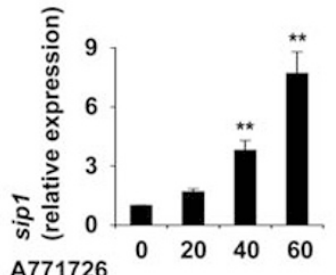

$(\mu \mathrm{M})$

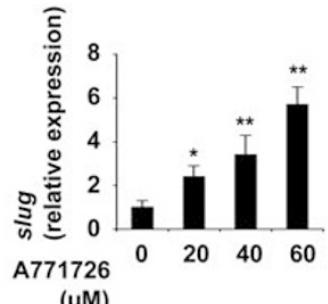

$(\mu \mathrm{M})$
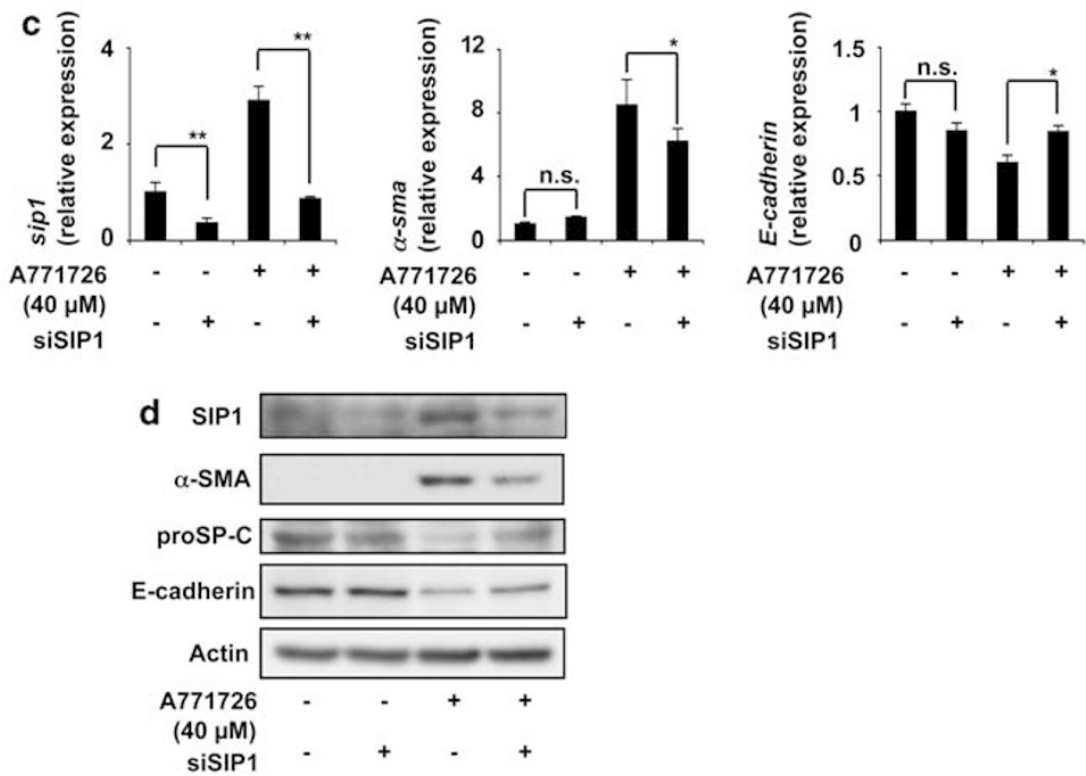

Figure 3 Effect of siRNA for SIP1 on A771726-induced EMT-like phenotypes. (a, b) A549 cells were incubated with the indicated concentrations of A771726 for $48 \mathrm{~h}$ (panel a) or $96 \mathrm{~h}$ (panel b). (c, d) A549 cells were transfected with siRNA for SIP1 (siSIP1 +) or nonspecific siRNA (siSIP1-). After $24 \mathrm{~h}$, the cells were incubated with A771726 $(40 \mu \mathrm{M})$ for $48 \mathrm{~h}$ (panel c) or $96 \mathrm{~h}$ (panel d). (Panels a-d) Protein and mRNA expressions were monitored and expressed as described in the legend of Figure 1. Values shown are mean \pm S.D. $(n=3) .{ }^{\star} P<0.05 ;{ }^{\star \star} P<0.01$; n.s., not significant

expression of Slug). Transfection of SIP1 siRNA suppressed the expression of sip1 mRNA and SIP1 protein in both the presence and the absence of A771726 treatment (Figure 3c and d). This transfection partially suppressed the A771726induced upregulation of $\alpha$-SMA expression and the downregulation of E-cadherin and proSP-C expression (Figure $3 c$ and d), suggesting that the upregulation of SIP1 expression is at least partly involved in A771726-induced EMT-like phenotypes. A771726-dependent upregulation of expression of SIP1 was also observed in primary cultured rat alveolar epithelial cells (Figure $2 \mathrm{~d}$ and $\mathrm{e}$ ).

It has also been reported that TGF- $\beta_{1}$ upregulates the expression of EMT-related transcription factors, including SIP1 ${ }^{23,24}$ However, as shown in Supplementary Figure S2a and b, A771726 did not significantly affect the mRNA expression of TGF- $\beta_{1}$ or the level of TGF- $\beta_{1}$ in the culture medium. Furthermore, LY364947, an inhibitor for TGF- $\beta$ receptor kinase, suppressed the changes in the expression of $\alpha$-SMA, E-cadherin and proSP-C in the presence of TGF- $\beta_{1}$ but not A771726 (Supplementary Figure S2c and d). It therefore appears that A771726-induced EMT-like phenotypes do not involve modulation of expression and activity of TGF- $\beta_{1}$.
Next, we tested the contribution of the Notch-signaling pathway to A771726-induced EMT-like phenotypes. This pathway, which is triggered by the binding between Notch receptors (Notch-1-4) and ligands (such as Jagged-1, 2 and Delta-like 1 (DII-1)), is mediated by two proteolytic cleavage events involving the Notch receptor. ${ }^{25}$ The second cleavage is catalyzed by $\gamma$-secretase, leading to secretion of the Notch intracellular domain (NICD), which then translocates to the nucleus to promote transcription of downstream genes. ${ }^{26}$ It was recently reported that activation of the Notch-signaling pathway induces EMT. ${ }^{27,28}$ As shown in Figure 4a and b, treatment of cells with $A 771726$ upregulated the expression of jagged-1, 2, dll-1 and notch-1, 3, 4 mRNAs and Jagged-1 and DII-1 in a dose-dependent manner. Furthermore, the level of $\mathrm{NICD}$ in the nuclear extract was increased in the presence of A771726 and this increase was suppressed by cotreatment with an inhibitor of $\gamma$-secretase, $N$-[N-(3,5-difluorophenacetylL-alanyl)]-S-phenylglycine $t$-butyl ester (DAPT) (Figure 4c), suggesting that the Notch-signaling pathway is activated by A771726. To test an idea that the Notch-signaling pathway is involved in A771726-induced EMT-like phenotypes, we examined the effect of DAPT on A771726-induced EMT-like phenotypes. As shown in Figure 4d and e, A771726-induced 

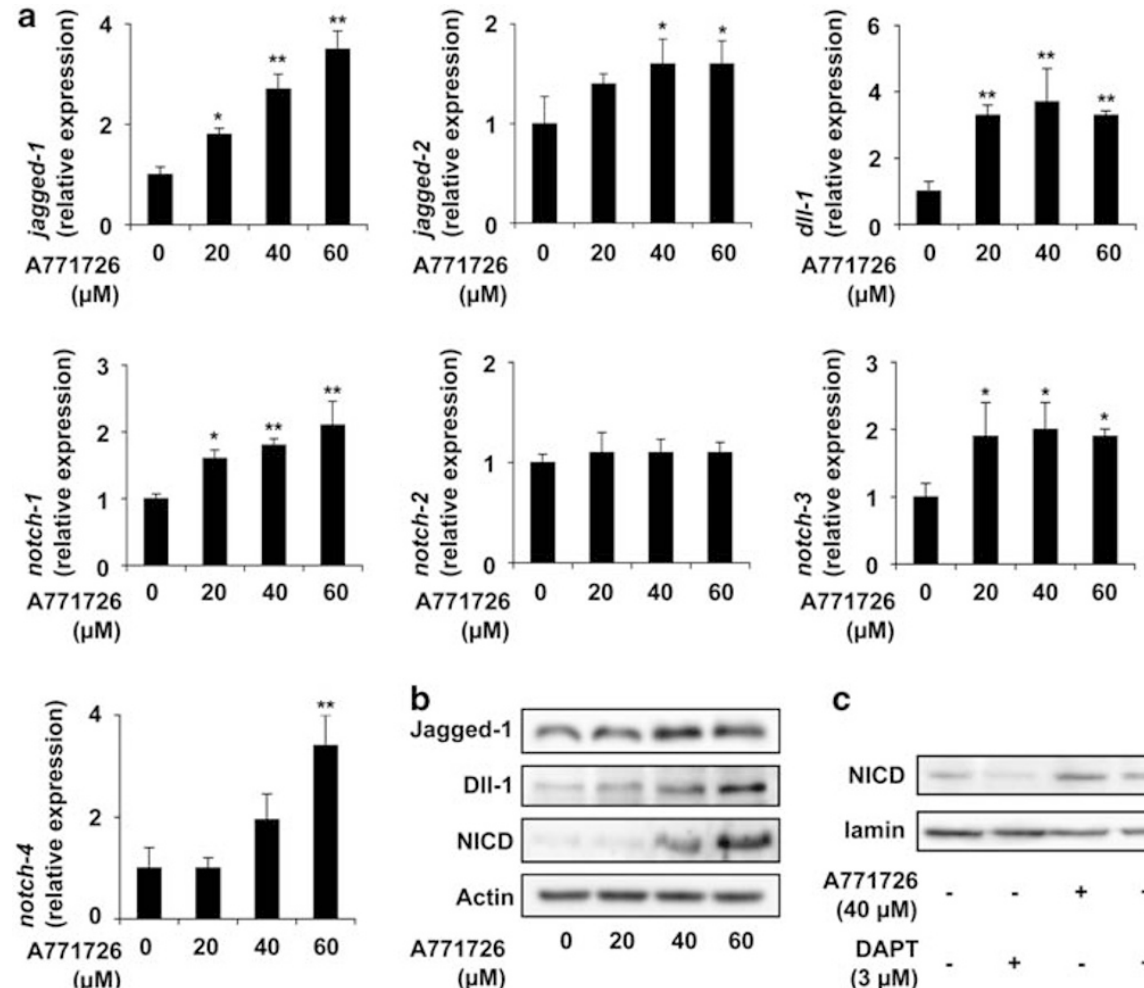

b

$(\mu \mathrm{M})$

( $\mu \mathrm{M})$

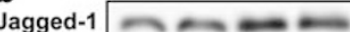

C
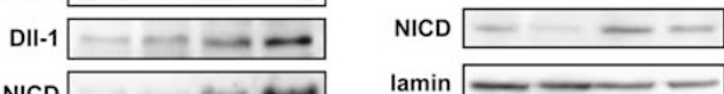

NICD

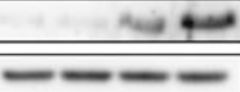

Actin

A771726
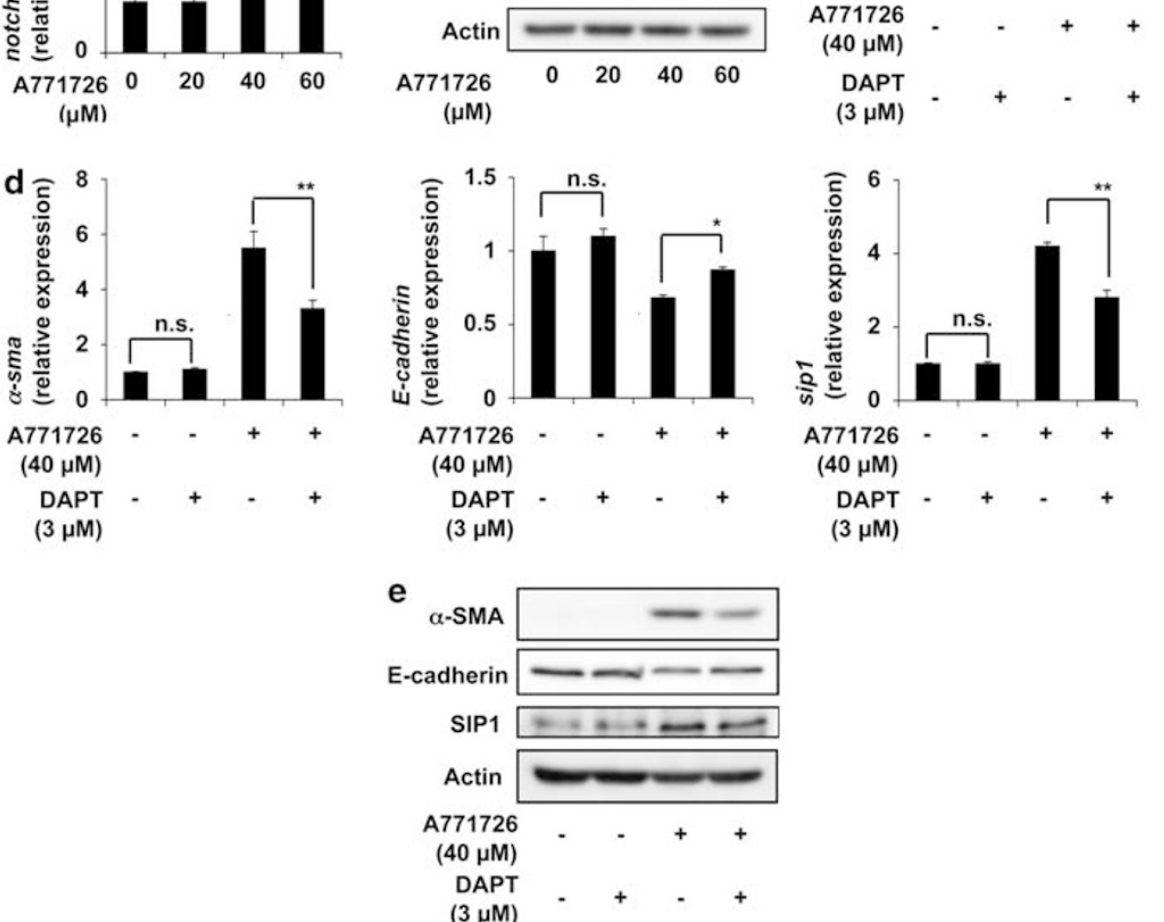

Figure 4 Involvement of the Notch-signaling pathway in A771729-induced EMT-like phenotypes. (a, b) A549 cells were incubated with the indicated concentrations of A771726 for $48 \mathrm{~h}$ (panel a) or for $96 \mathrm{~h}$ (panel b). (c-e) A549 cells were preincubated with or without DAPT ( $3 \mu \mathrm{M})$ for $1 \mathrm{~h}$ and further incubated with or without A771726 $(40 \mu \mathrm{M})$ for $48 \mathrm{~h}$ (panels $\mathrm{c}, \mathrm{d}$ ) or $96 \mathrm{~h}$ (panel e) in the presence of the same concentrations of DAPT as in the preincubation step. (Panels a, b, $d, e)$ mRNA and protein expression was monitored and expressed as described in the legend of Figure 1. (Panel c) Nuclear extracts were prepared and analyzed by immunoblotting with an antibody against NICD or lamin. Values shown are mean \pm S.D. $(n=3) .{ }^{*} P<0.05 ;{ }^{\star \star} P<0.01$; n.s., not significant

alterations in the mRNA and protein expression of $\alpha$-SMA, E-cadherin and SIP1 were partially suppressed by DAPT, suggesting that the Notch-signaling pathway does contribute to A771726-induced EMT-like phenotypes. A771726-dependent upregulation of expression of jagged-1 and notch-1
mRNAs and Jagged-1 and NICD was also observed in primary cultured rat alveolar epithelial cells (Figures $2 d$ and $e$ ).

To test whether the inhibition of $\mathrm{DHODH}$ is involved in the EMT-inducing activity of A771726, we first examined the effect of siRNA for DHODH on the expression of EMT-related genes. 

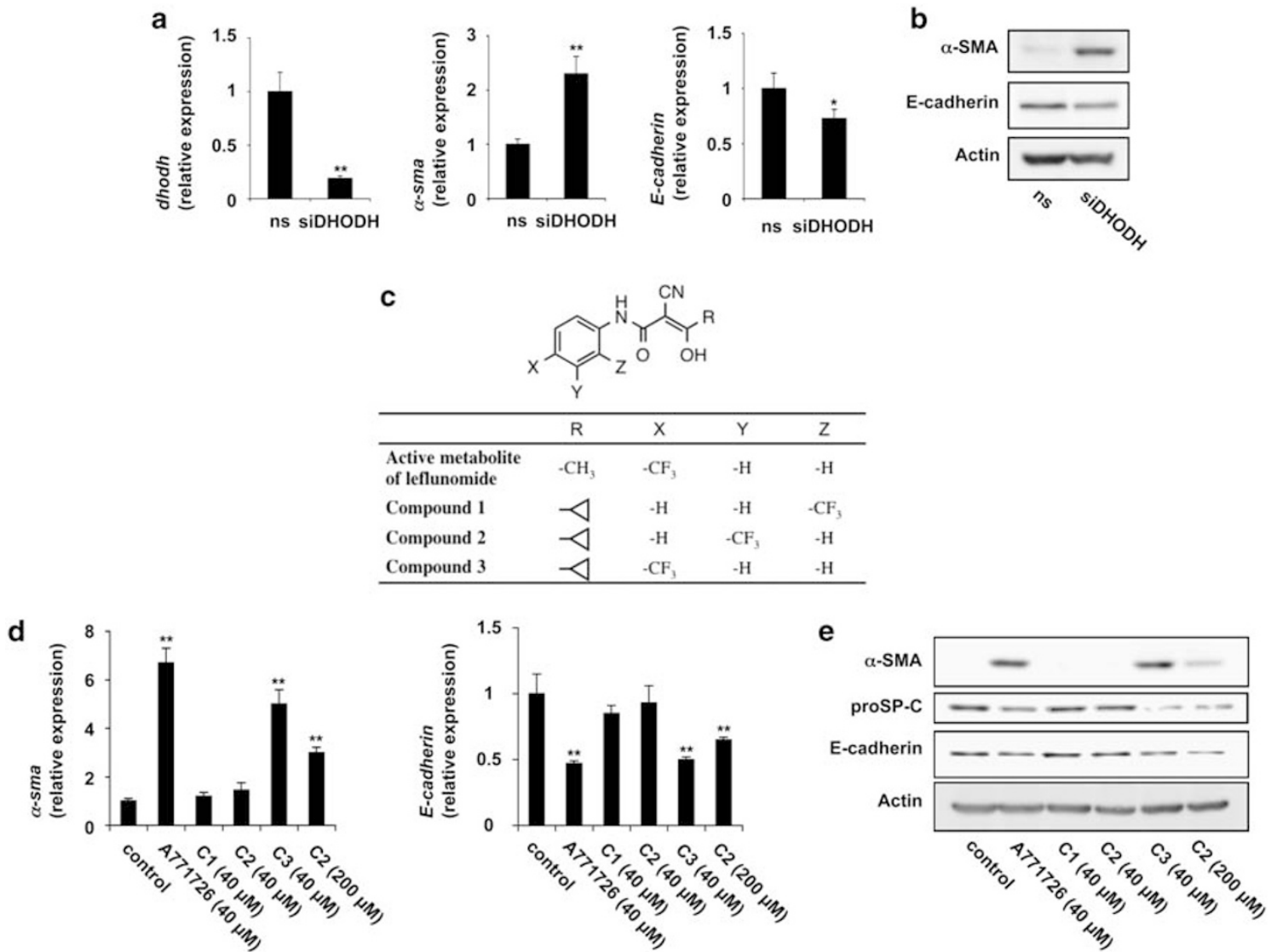

Figure 5 Involvement of DHODH inhibition in A771729-induced EMT-like phenotypes. (a, b) A549 cells were transfected with siRNA for DHODH (siDHODH) or nonspecific siRNA (ns) for $72 \mathrm{~h}$. (d, e) A549 cells were incubated with the indicated concentration of each compound for $48 \mathrm{~h}$ (panel d) or $96 \mathrm{~h}$ (panel e). (Panels a, b, d, e) Protein and mRNA expressions were monitored and expressed as described in the legend of Figure 1. The chemical structures of the compounds are shown in $\mathbf{c}$. Values shown are mean \pm S.D. $(n=3) .{ }^{*} P<0.05 ;{ }^{* *} P<0.01$

Transfection of siRNA for DHODH altered the mRNA and protein expression of $\alpha$-SMA and E-cadherin (Figure 5a and b). A number of A771726 analogs have been synthesized, and their ability to inhibit DHODH was revealed. ${ }^{29}$ The DHODH-inhibitory ability of compound 3 is similar to that of A771726; however, that of compound 2 is markedly less, and compound 1 is inert in this context. ${ }^{29}$ As illustrated in Figure $5 d$ and $e$, compound 3 induced EMT-like phenotypes to a similar extent to that observed with A771726. Compound 2 also induced EMT-like phenotypes, but only at a higher concentration, whereas compound 1 had no effect (Figure $5 d$ and e). Taken together, these results suggest that $A 771726$ induces EMT-like phenotypes through inhibition of DHODH.

We further examined the effect of supplementing the cultures with exogenous uridine. As shown in Figure $6 a$ and $b$, the addition of uridine to the culture medium suppressed the A771726-induced EMT-like phenotypes. Furthermore, it also suppressed the A771726-induced upregulation of expression of sip1, notch-1 and jagged-1 mRNAs and SIP1, NICD and Jagged-1 (Figure 6a and b). Uridine-dependent suppression of A771726-induced EMT-like phenotypes was also observed in primary cultured rat alveolar epithelial cells (Figure $2 f$ and g). These results further support the notion that $A 771726$ induces EMT-like phenotypes through inhibition of DHODH.
We also found that the addition of cytidine suppressed A771726-induced EMT-like phenotypes (data not shown). As it is known that uridine and cytidine can be synthesized from each other, ${ }^{30}$ it seems that these phenotypes are mediated through depletion of the intracellular pool of pyrimidine.

Therefore, we next tested whether the induction of EMT-like phenotypes is specific for inhibition of pyrimidine synthesis or can be observed with inhibition of purine synthesis using 6-mercaptopurine (6-MP), an inhibitor of purine synthesis. ${ }^{30}$ Treatment of A549 cells with $100 \mu \mathrm{M}$ 6-MP inhibited cell growth to a similar extent to that observed with $40 \mu \mathrm{M}$ A771726 (data not shown). As shown in Figure 6c, treatment of cells with $100 \mu \mathrm{M}$ 6-MP upregulated the expression of $\alpha$-sma mRNA and downregulated the expression of E-cadherin mRNA. However, 6-MP had no effect on the expression of sip 1 and notch-1 mRNAs and protein expression of $\alpha$-SMA, SIP1, NICD and proSP-C, and downregulated the expression of jagged-1 mRNA and Jagged-1 (Figure 6c and d), suggesting that inhibition of pyrimidine synthesis rather than purine synthesis preferentially induces EMT-like phenotypes.

Effect of leflunomide on bleomycin-induced pulmonary fibrosis. As described in the 'Introduction' section, induction 

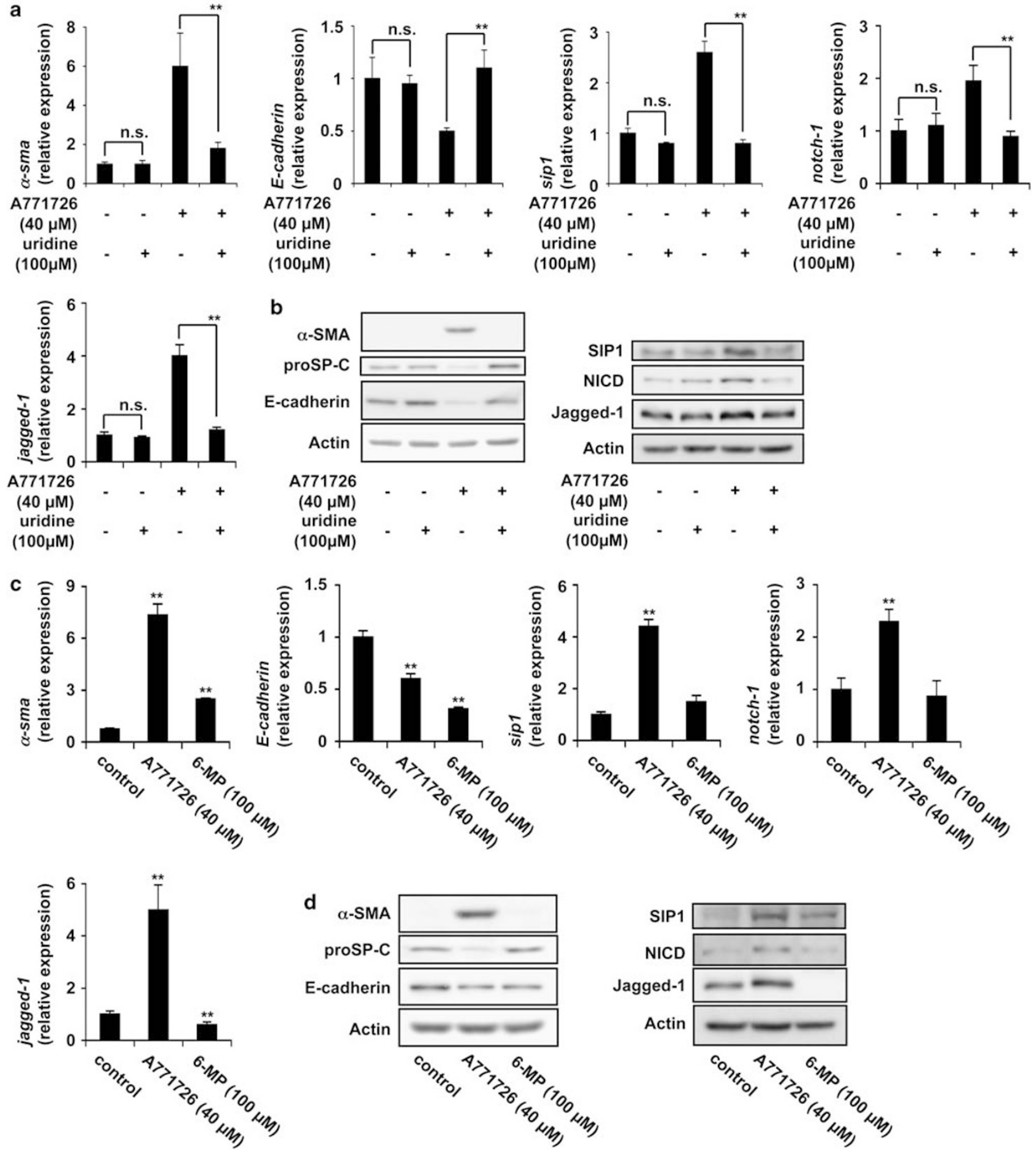

Figure 6 Involvement of inhibition of pyrimidine synthesis in A771729-induced EMT-like phenotypes. A549 cells were incubated with the indicated concentrations of A771726 (a-d), uridine (panels a, b) and 6-MP (panels c, d) for $48 \mathrm{~h}$ (panels a, c) or $96 \mathrm{~h}$ (panels b, d). Protein and mRNA expressions were monitored and expressed as described in the legend of Figure 1. Values shown are mean \pm S.D. $(n=3) .{ }^{* \star} P<0.01$

of EMT of lung epithelial cells has an important role in pulmonary fibrosis, with the in vitro results outlined above implicating leflunomide in this process. To investigate this further, we first examined whether EMT is induced in the mouse lung by oral administration of leflunomide alone, finding no significant effect at concentrations of up to $100 \mathrm{mg} / \mathrm{kg}$ (data not shown). Next, we tested the idea that leflunomide stimulates EMT-like phenomenon in the presence of other fibrosis-inducing stimuli, such as bleomycin. A once-only (at day 0 ) intratracheal administration of bleomycin $(5 \mathrm{mg} / \mathrm{kg})$ 

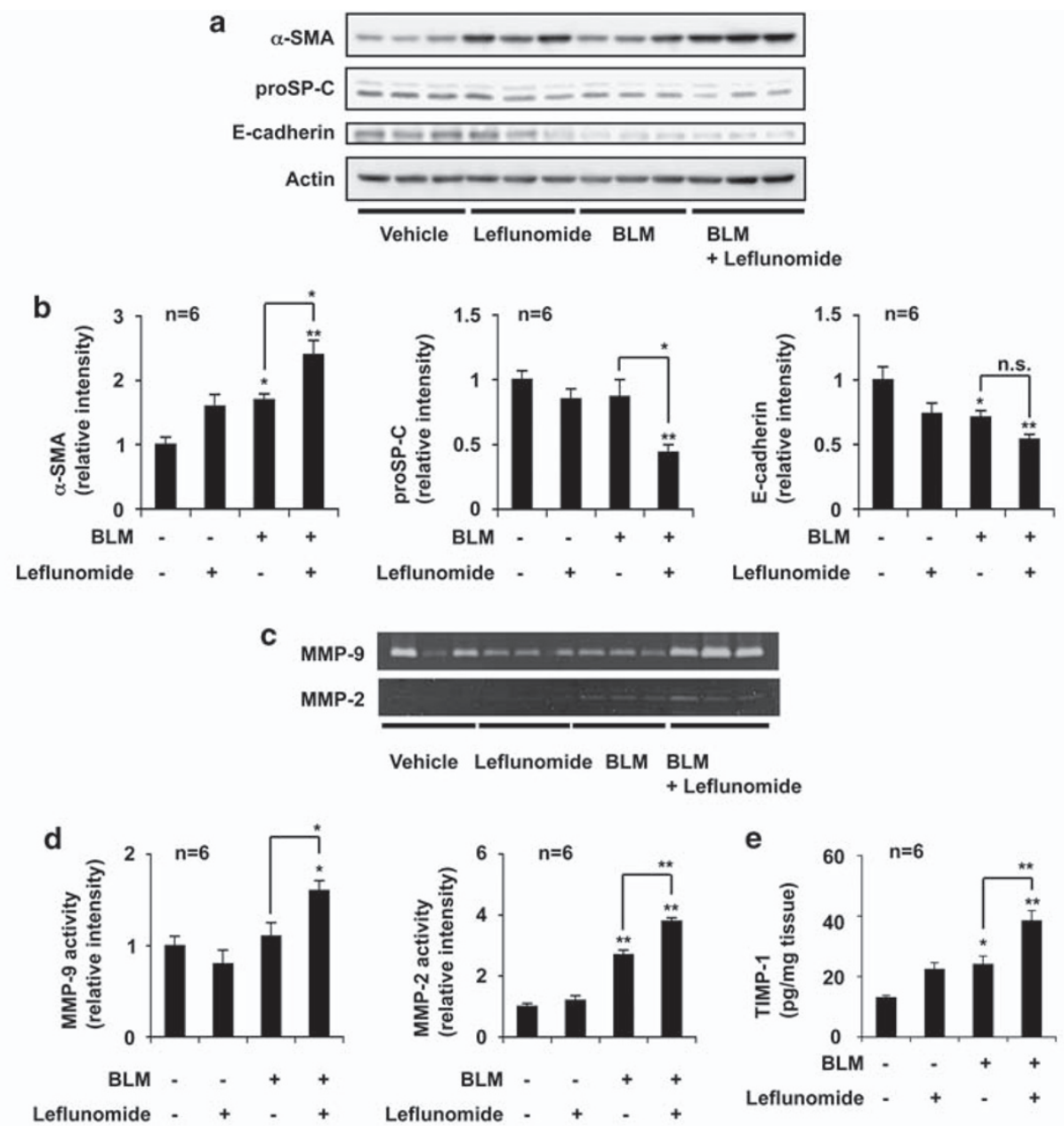

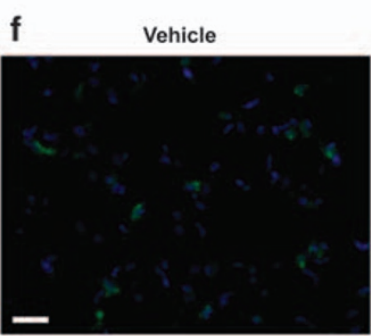

BLM
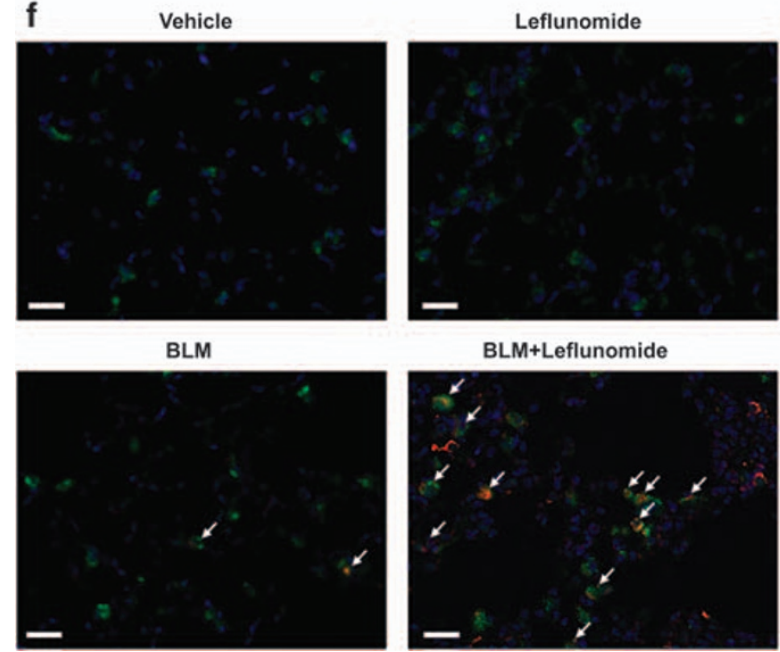

BLM+Leflunomide

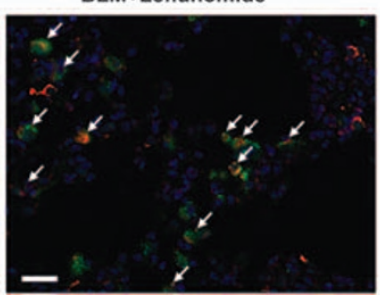

g

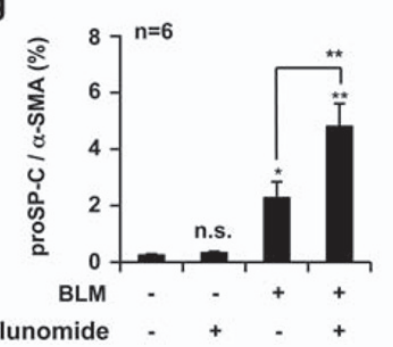

h

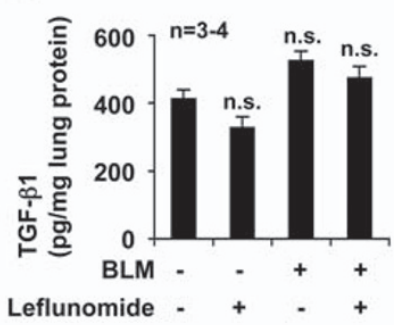

Figure 7 Induction of EMT-like phenotypes by administration of bleomycin and leflunomide. (a-h) Mice were treated once only with or without $0.5 \mathrm{mg} / \mathrm{kg}$ bleomycin (BLM) (day 0 ), then orally administered leflunomide $(40 \mathrm{mg} / \mathrm{kg}$ ) or vehicle once per day for 9 days (from day 5 to day 14). (Panel a) Total protein was extracted from pulmonary tissues at day 14 and analyzed with immunoblotting with an antibody against $\alpha$-SMA, proSP-C, E-cadherin or actin. (Panel b) The intensity of the band of $\alpha$-SMA, proSP-C and E-cadherin was determined (one of two gels is shown in panel a) and expressed relative to the results obtained in control mice $(n=6)$. (Panel c) The activity of MMP-9 and MMP-2 in pulmonary tissues at day 14 was measured as described in the legend of Figure 1. (Panel d) the clear band intensity was determined (one of two gels is shown in panel c) and expressed relative to the control $(n=6)$. (Panel e) The level of TIMP-1 in pulmonary tissues at day 14 was determined by ELISA ( $n=6)$. (Panel $f$ ) Sections of pulmonary tissues were prepared at day 14 and subjected to immunohistochemical analysis with an antibody against $\alpha$-SMA (red) and proSP-C (green) (scale bar, $50 \mu \mathrm{m}$ ). (Panel g) The ratio of EMT-induced cells (coexpression of $\alpha$-SMA and proSP-C) to total cells (500-800 cells) was determined $(n=6)$. (Panel h) The level of TGF- $\beta 1$ in pulmonary tissue at day 14 days was determined by ELISA $(n=3-4)$. Values are mean \pm S.E.M. ${ }^{\star} P<0.05 ;{ }^{* *} P<0.01$; n.s., not significant 


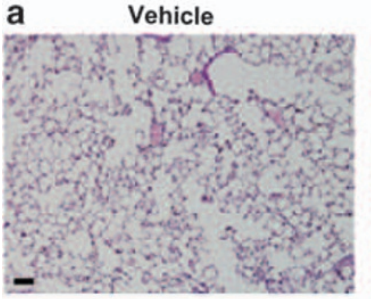

BLM
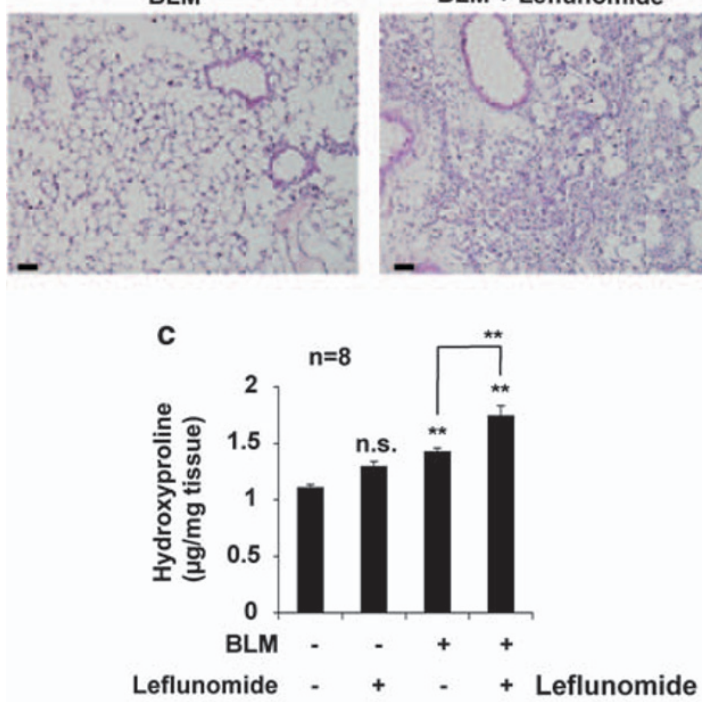

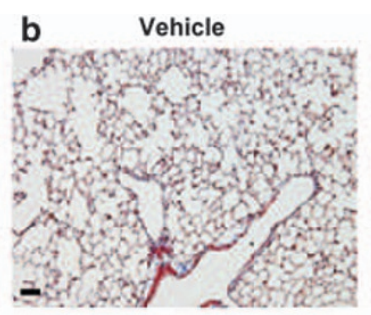

BLM + Leflunomide

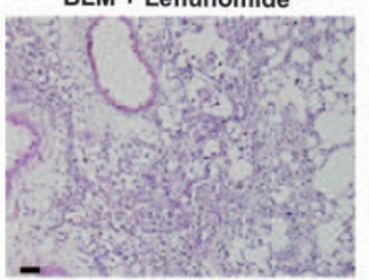

BLM
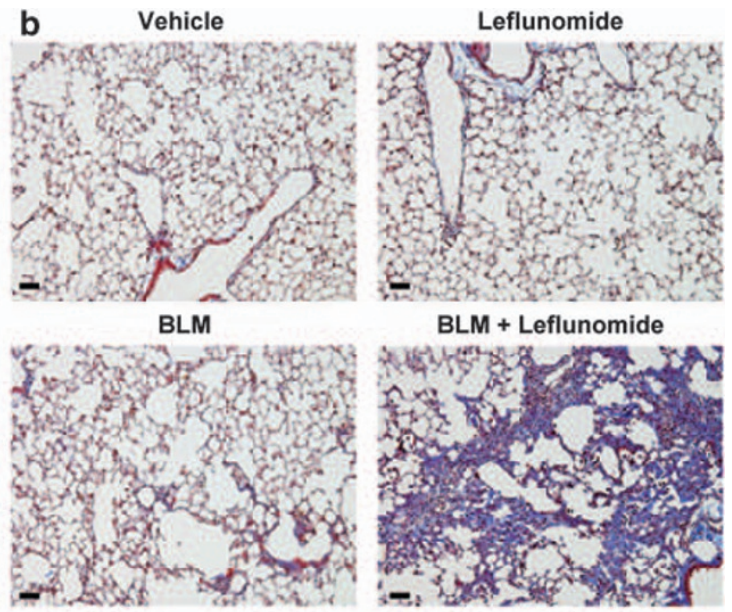

BLM + Leflunomide

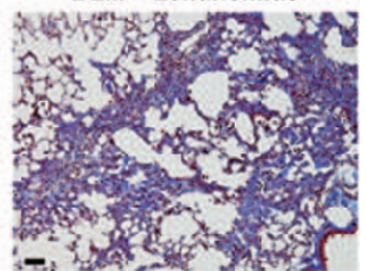

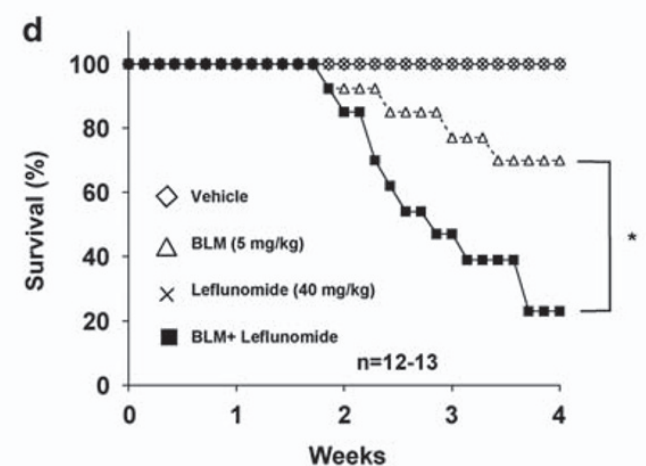

Figure 8 Effect of leflunomide on bleomycin-induced pulmonary fibrosis. (a-c) Mice were treated once only with or without $0.5 \mathrm{mg} / \mathrm{kg}$ bleomycin (BLM) (day 0), then orally administered leflunomide $(40 \mathrm{mg} / \mathrm{kg}$ ) or vehicle once per day for 9 days (from day 5 to day 14). (Panels a, b) Sections of pulmonary tissue were prepared at day 14 and subjected to histological examination ( $\mathrm{H} \& \mathrm{E}$ staining (panel a) or Masson's trichrome staining (panel b)) as described in the 'Materials and Methods' section (scale bar, $50 \mu \mathrm{m}$ ). (Panel c) The pulmonary hydroxyproline level at day 14 was determined as described in the 'Materials and Methods' section ( $n=8)$. (d) Mice were treated once only with BLM $(5 \mathrm{mg} / \mathrm{kg})$ at day 0 and were then orally administered leflunomide $(40 \mathrm{mg} / \mathrm{kg})$ once per day for 3 weeks (from day 7 to day 28$)$. The survival rate of the animals was monitored $(n=12-13)$. Values are mean \pm S.E.M. ${ }^{*} P<0.05 ;{ }^{\star \star} P<0.01$; n.s., not significant

induced apparent EMT-like phenomenon 14 days after treatment (see below). To examine the effect of leflunomide on the bleomycin-induced EMT-like phenomenon, we used a lower dose of bleomycin $(0.5 \mathrm{mg} / \mathrm{kg})$. Immunoblotting analysis of pulmonary tissues revealed that administration of bleomycin alone at this dose slightly increased or decreased the level of $\alpha$-SMA or E-cadherin and proSP-C, respectively, an effect that was further stimulated by simultaneous administration of leflunomide $(40 \mathrm{mg} / \mathrm{kg})$, although the results were not always statistically significant (Figure $7 a$ and b). We also measured MMP activity and the level of TIMP-1 by gelatin zymography and ELISA, respectively, and found that these were slightly elevated in response to administration of bleomycin alone, an effect that was further stimulated by simultaneous administration of leflunomide (Figure 7c-e), overall suggesting that leflunomide stimulates bleomycininduced EMT-like phenomenon.

To test this idea further, we then used immunohistochemical analysis to detect cells with positive expression of both $\alpha$-SMA and proSP-C, a marker of EMT of lung epithelial cells. ${ }^{14}$ As shown in Figure $7 f$ and $g$, a few double-positive cells were detected in lung sections prepared from bleomycintreated mice; this number being dramatically increased by simultaneous administration of leflunomide. Administration of leflunomide alone had no such effect (Figure $7 f$ and $g$ ).

We next measured the pulmonary level of TGF- $\beta 1$ and found that administration of bleomycin $(0.5 \mathrm{mg} / \mathrm{kg})$ and leflunomide, either alone or in combination had no significant effect (Figure $7 \mathrm{~h}$ ). Administration of bleomycin $(0.5 \mathrm{mg} / \mathrm{kg}$ ) and leflunomide also did not affect the pulmonary level of connective tissue growth factor (CTGF) (Supplementary Figure S3).

We then examined the effect of administration of leflunomide on bleomycin-induced pulmonary fibrosis by monitoring histopathological changes and pulmonary hydroxyproline levels (an indicator of collagen levels). Histopathological analysis of pulmonary tissue using hematoxylin and eosin staining showed that the simultaneous administration of leflunomide $(40 \mathrm{mg} / \mathrm{kg})$ and bleomycin $(0.5 \mathrm{mg} / \mathrm{kg})$ induced severe pulmonary damage (thickened and edematous alveolar walls and interstitium, and infiltration of leucocytes) (Figure 8a). Administration of either leflunomide or bleomycin alone did not cause such clear pulmonary damage (Figure 8a). Masson's trichrome staining of collagen revealed that administration of bleomycin caused slight collagen deposition, an effect, which was greatly exacerbated by 


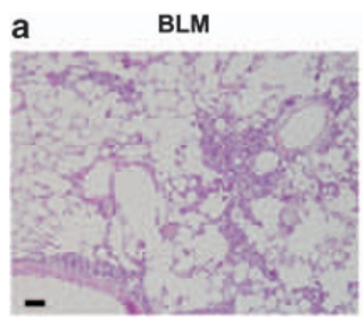

BLM+uridine

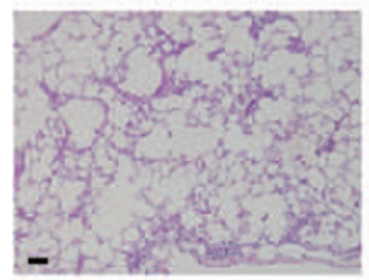

BLM+Leflunomide

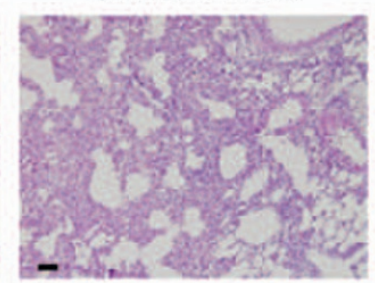

BLM+Leflunomide+uridine

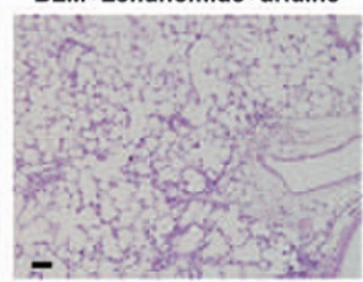

BLM

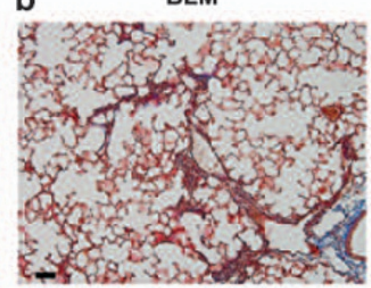

BLM+uridine

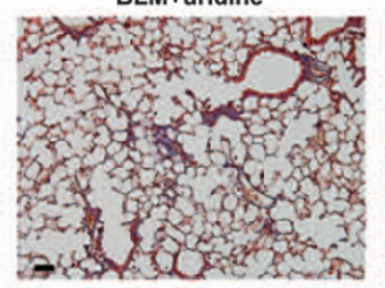

BLM+Leflunomide

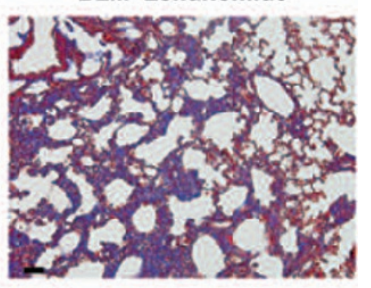

BLM+Leflunomide+uridine

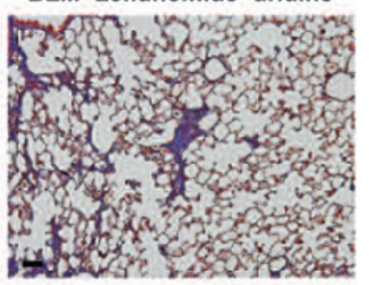

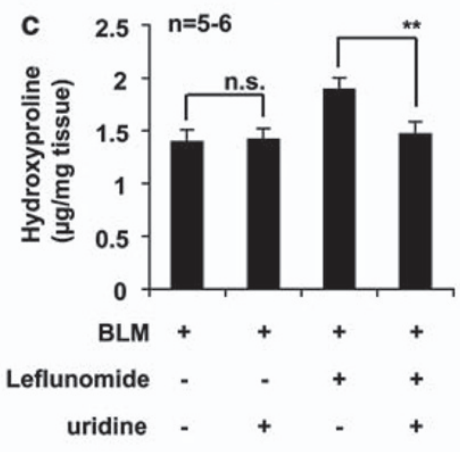

d

BLM

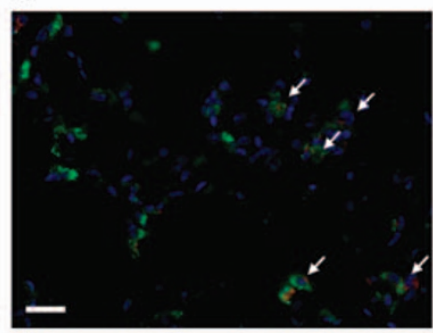

BLM+uridine

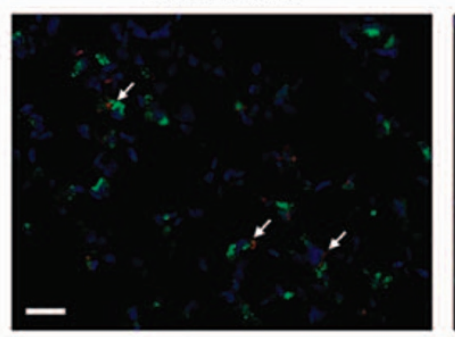

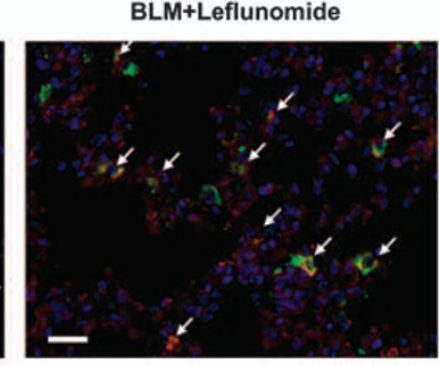

BLM+Leflunomide+uridine

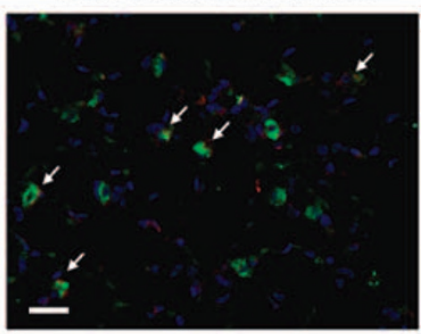

Leflunomide - -++

uridine - + - +

Figure 9 Effect of coadministration of uridine on leflunomide-induced exacerbation of pulmonary fibrosis and EMT-like phenotypes. (a-c) Mice were treated once only with or without $0.5 \mathrm{mg} / \mathrm{kg}$ bleomycin (BLM) (day 0), then administered leflunomide $(40 \mathrm{mg} / \mathrm{kg}$ ) and uridine (50 mg/kg) once per day for 9 days (from day 5 to day 14$)$. (Panels a, b) Sections of pulmonary tissue were prepared at day 14 and subjected to histological examination as described in the legend of Figure 8 (scale bar, $50 \mu \mathrm{m}$ ). (Panel c) The pulmonary hydroxyproline level was determined at day 14 as described in the legend of Figure $8(n=5-6)$. (d, e) Immunohistochemical analysis was performed as described in the legend of Figure 7 (scale bar, $50 \mu \mathrm{m})(n=5)$. Values are mean \pm S.E.M. ${ }^{* \star} P<0.01$; ${ }^{\star} P<0.05$; n.S., not significant

simultaneous administration of leflunomide (Figure 8b). The pulmonary hydroxyproline level was slightly increased by administration of bleomycin alone, but this effect was further enhanced by simultaneous administration of leflunomide (Figure 8c). These results suggest that administration of leflunomide exacerbates bleomycin-induced pulmonary fibrosis.

We next examined the effect of leflunomide on the survival of mice treated with bleomycin. As shown in Figure 8d, administration of bleomycin alone caused death, the rate of which was accelerated by simultaneous administration of leflunomide.
To test whether leflunomide exacerbates bleomycininduced pulmonary fibrosis through inhibition of $\mathrm{DHODH}$, we examined the effect of coadministration of uridine. As shown in Figure $9 a-c$, coadministration of uridine clearly suppressed pulmonary tissue damage, collagen deposition and increases in pulmonary hydroxyproline levels observed in mice treated with both bleomycin and leflunomide. We also found a decrease in the number of cells expressing both $\alpha$-SMA and proSP-C in mice that had been coadministered uridine (Figure 9d and e). These findings suggest that the exacerbation of bleomycin-induced pulmonary fibrosis by 
leflunomide is mediated by its inhibitory effect on $\mathrm{DHODH}$ and resulting stimulation of bleomycin-induced EMT-like phenomenon.

\section{Discussion}

Although drug-induced ILD, particularly interstitial pneumonia associated with pulmonary fibrosis, is a serious clinical concern, the molecular mechanism governing this phenomenon is unknown, leading to the lack of a suitable animal model. Consequently, neither a clinical protocol for the treatment of drug-induced ILD nor an assay system to eliminate candidate drugs with the potential to cause this type of side effect has been established. A number of previous reports have suggested that cytotoxic and allergy-inducing effects of the drugs are involved in drug-induced ILD. ${ }^{3-5,19}$ In this study, for the first time, we focused on the EMT of lung epithelial cells in a bid to understand the mechanism of drug-induced ILD (pulmonary fibrosis).

When we examined the EMT-inducing abilities of drugs known to induce ILD clinically, we found that A771726 and methotrexate produced EMT-like phenotypes. The concentration of methotrexate used was much higher than its plasma concentration at a clinical dose (approximately $0.01-0.2 \mu \mathrm{M}) .{ }^{31}$ On the other hand, A771726 induced EMTlike phenotypes at concentrations similar to those obtained in the plasma when administered at therapeutic levels (approximately $40-350 \mu \mathrm{M}) .^{32}$ Thus, we considered that induction of EMT-like phenotypes by A771726 is clinically relevant and investigated the underlying molecular mechanism. Studies on other cell types have shown that A771726 induces apoptosis and diminishes proliferation in myeloma cells ${ }^{33}$ and inhibits proliferation and collagen synthesis and induces apoptosis in hepatic stellate cells, ${ }^{34}$ suggesting that $A 771726$ affects cell physiology differently depending on cell-type species.

Among the transcription factors known to induce EMT, we found that both SIP1 and Slug mRNA expression was upregulated by $A 771726$ and that transfection of cells with siRNA for SIP1 partially suppressed the A771726-induced EMT-like phenotypes, suggesting that SIP1 has a role in this phenomenon. However, although it is well known that TGF- $\beta 1$ induces EMT through transcription factors that include SIP $1,{ }^{23}$ the lack of involvement of the TGF- $\beta$-signaling pathway was suggested by the fact that (1) TGF- $\beta 1$ expression and the level of TGF- $\beta 1$ in the culture medium were not affected by A771726 and (2) an inhibitor of the TGF- $\beta$ signaling pathway did not affect the A771726-induced EMTlike phenotypes. This led us to investigate the involvement of the Notch-signaling pathway, which has recently been reported to have an important role not only in EMT but also in pulmonary fibrosis. ${ }^{27,35}$ Expression of some Notch ligands and receptors was upregulated by A771726, and an inhibitor for this pathway (DAPT) partially suppressed the A771726induced EMT-like phenotypes, suggesting the involvement of the Notch-signaling pathway to this phenomenon. Furthermore, although it is known that $A 771726$ has various activities other than inhibition of $\mathrm{DHODH}$, including inhibition of tyrosine kinase and cyclooxygenase-2,36,37 we clearly showed that the primary target of $A 771726$ for induction of EMT is DHODH based on the following observations: (1) transfection of cells with siRNA for DHODH induced EMT-like phenotypes, (2) among the A771726 analogs, the ability to induce EMT-like phenotypes correlated with the ability to inhibit DHODH and (3) the addition of uridine to the culture medium completely suppressed the A771726-induced EMT-like phenotypes. However, how inhibition of DHODH causes EMT remains unclear.

We found that administration of leflunomide alone did not induce EMT-like phenomenon in mouse lung. As one of the risk factors for leflunomide-induced ILD is preexisting pulmonary fibrosis, ${ }^{20,38}$ we hypothesized that leflunomide stimulates EMT-like phenotypes in the presence of other fibrosisinducing stimuli. In fact, we found that the administration of leflunomide stimulated bleomycin-induced EMT-like phenotypes in the mouse lung, an effect which was suppressed by coadministration of uridine. This is the first demonstration that administration of a drug known to induce ILD clinically modulates EMT-like phenotypes in vivo. We also found that administration of leflunomide stimulated bleomycin-induced pulmonary fibrosis, and that this was suppressed by coadministration of uridine. Taken together, our findings suggest that leflunomide exacerbates bleomycin-induced pulmonary fibrosis through inhibition of $\mathrm{DHODH}$ and the resulting induction of EMT in lung epithelial cells. As described in the 'Introduction' section, lung myofibroblasts are produced by both activation of lung fibroblasts and EMT of lung epithelial cells. ${ }^{9}$ We found that A771726 did not affect the expression of $\alpha$-SMA and collagen I in HFL1 (human lung fibroblast) cells (data not shown), suggesting that A771726 does not activate fibroblasts to form myofibroblasts.

These results suggest that the EMT-inducing ability of leflunomide is involved in its exacerbation of pulmonary fibrosis. This finding is an important step toward addressing the molecular mechanism of drug-induced ILD, as well as the mechanism governing the racial differences for susceptibility to ILD induced by the drug. It is possible that the susceptible phenotype of Japanese patients is due to a specific polymorphism in genes related to EMT. Furthermore, the exacerbation of pulmonary fibrosis by leflunomide can be used as an animal model of drug-induced pulmonary fibrosis, allowing screening to eliminate candidate drugs for the potential side effects.

\section{Materials and Methods}

Chemicals and animals. Paraformaldehyde, fetal bovine serum (FBS), 4-(dimethylamino)-benzaldehyde (DMBA), chloramine T, Orange G, uridine, 6-MP, LY364947 and an antibody against $\alpha$-SMA were obtained from Sigma (St. Louis, MO, USA). TGF- $\beta 1$ was acquired from Funakoshi Co. (Tokyo, Japan). Bleomycin was purchased from Nippon Kayaku (Tokyo, Japan). DAPT was from the Peptide Institute Inc. (Tokyo, Japan). ELISA kits for TGF- $\beta 1$ and TIMP-1 were obtained from R\&D Systems Inc. (Minneapolis, MN, USA). The RNeasy kit and HiPerFect were obtained from Qiagen (Valencia, CA, USA), the PrimeScript first-strand CDNA Synthesis Kit was from Takara Bio (Ohtsu, Japan), and the iQ SYBR Green Supermix was from Bio-Rad Laboratories (Hercules, CA, USA). Antibodies against SIP1, jagged-1, DII-1, Notch-1, actin and lamin were purchased from Santa Cruz Biotechnology Inc. (Santa Cruz, CA, USA) and that against E-cadherin was from Zymed Laboratories (San Francisco, CA, USA). An antibody against proSP-C was from Millipore Co. (Bedford, MA, USA) and that against Slug was from Cell Signaling (Bedford, MA, USA). Alexa Fluor 594 (or 488) goat anti-mouse IgG and Alexa Fluor 488 goat anti-rabbit IgG were obtained from Invitrogen (Carlsbad, CA, USA). Mounting medium for immunohistochemical analysis (VECTASHIELD) was from Vector Laboratories (Burlingame, CA, USA). Cytospin 4 was purchased from 
Thermo Electron Co. (Waltham, MA, USA). Leflunomide, A771726, gefitinib, imatinib, amiodarone, methotrexate, L-hydroxyproline, azophloxin and aniline blue were from Wako Pure Chemicals (Tokyo, Japan). Xylidine ponceau was from WALDECK GmbH and Co. (Muenster, Germany), and Mayer's hematoxylin, 1\% eosin alcohol solution, mounting medium for histological examination (malinol) and Weigert's iron hematoxylin were purchased from MUTO Pure Chemicals (Tokyo, Japan). 4,6-Diamino-2-phenylindole (DAPI) was from Dojindo (Kumamoto, Japan). ELISA kits for CTGF were obtained from Pepro Tech Inc. (Rocky Hill, NJ, USA). A771726 derivatives (compounds 1, 2 and 3) were synthesized as described previously. ${ }^{29}$ Male C57BL/6 wild-type mice (6-8 weeks old) were used throughout the study. Male Wistar rats (6-8 weeks of age) were obtained from Kyudoh Co. (Kumamoto, Japan). The experiments and procedures described in this study were carried out in accordance with the Guide for the Care and Use of Laboratory Animals as adopted and promulgated by the National Institutes of Health, and were approved by the Animal Care Committee of Kumamoto University.

Cell culture and immunostaining. A549 cells were cultured in DMEM medium supplemented with $10 \% \mathrm{FBS}, 100 \mathrm{Units} / \mathrm{ml}$ penicillin and $100 \mu \mathrm{g} / \mathrm{ml}$ streptomycin in a humidified atmosphere of $95 \%$ air with $5 \% \mathrm{CO}_{2}$ at $37^{\circ} \mathrm{C}$.

For immunostaining, A549 cells were grown in the Lab-Tek II chamber slide system (Nalge Nunc International, Rochester, NY, USA). Cells were fixed in ice-cold acetone for $20 \mathrm{~min}$, blocked with goat serum for $15 \mathrm{~min}$ and then incubated for $12 \mathrm{~h}$ with antibody against E-cadherin or $\alpha$-SMA in the presence of $2.5 \%$ bovine serum albumin (BSA), before finally being incubated for $3 \mathrm{~h}$ with Alexa Fluor 488 goat antimouse IgG. Samples were mounted with VECTASHIELD. Images were captured on a confocal laser-scanning fluorescence microscope (FLUOVIEW FV500-IX-UV, Olympus, Tokyo, Japan).

Primary cultured alveolar epithelial cells were prepared from the lungs of adult pathogen-free male Wistar rats, as described previously. ${ }^{39,40}$ Briefly, trypsin was used to dissociate the cells from the lung tissues. The resultant cell suspension was incubated on petri dishes for $60 \mathrm{~min}$ to remove other types of cells. Cells were suspended in DMEM and cultured for $24 \mathrm{~h}$ to remove nonadherent cells. The purity of the type II cells was $\sim 95 \%$, as described previously. ${ }^{39}$

Real-time RT-PCR analysis. Real-time RT-PCR was performed as described previously, ${ }^{41}$ with some modifications. Total RNA was extracted from pulmonary tissues using an RNeasy kit, according to the manufacturer's protocol. Samples (2.5 $\mu \mathrm{g}$ RNA) were reverse transcribed using a first-strand cDNA synthesis kit. Synthesized CDNA was used in real-time RT-PCR (Chromo 4 instrument; Bio-Rad Laboratories) experiments using iQ SYBR GREEN Supermix, and analyzed with Opticon Monitor Software (Tokyo, Japan). Specificity was confirmed by electrophoretic analysis of the reaction products and by the inclusion of templateor reverse transcriptase-free controls. To normalize the amount of total RNA present in each reaction, actin cDNA was used as an internal standard.

Primers were designed using the Primer3 website. The primers used were (name: forward primer, reverse primer): For humans, $\alpha$-sma: $5^{\prime}$-CATCATGCGTCTGGATCTGG-3', $5^{\prime}$-GGACAATCTCACGCTCAGCA-3'; tgf- $\beta 1$ : $5^{\prime}$-AA GGACCTCGGCTGGAAGTG-3', 5'-CCGGGTTATGCTGGTTGTA-3'; twist: $5^{\prime}$-GT CCGCAGTCTTACGAGGAG-3', $5^{\prime}$-TGAATCTTGCTCAGCTTGTCC-3'; snail: $5^{\prime}$-G CCTAGCGAGTGGTTCTTCT-3', 5'-TAGGGCTGCTGGAAGGTAAA-3'; slug: $5^{\prime}$ GAGCATTTGCAGACAGGTCA-3', 5'-ACAGCAGCCAGATTCCTCAT-3'; sip 1: 5'-TACGGATCCCGAAACGATAC-3', 5'-CCTCGTGGTCTGATTTGGTT-3'; dhodh: 5'-ACATTGCCAGTGTGGTCAAA-3', 5'-TCAGCCCTCCTGTTTCAGAG-3'; timp-1: 5'-TGACATCCGGTTCGTCTACA-3', 5'-TGCAGTTTTCCAGCAATGAG-3'; mmp-2: 5'-AGTCTGAAGAGCGTGAAG-3', 5'-CCAGGTAGGAGTGAGAATG-3'; mmp-9: 5'-TGACAGCGACAAGAAGTG-3', 5'-CAGTGAAGCGGTACATAGG-3'; notch-1: 5'-CAGCACCTTGGCGGTCTCGTA-3', 5'-CAATGTGGATGCCGCAGTTGTG-3'; notch-2: 5'-CAGGGGGCACTGACAGTAAT-3', 5'-GGAATGCAAGTGCAGAGTG G-3'; notch-3: 5'-AGATTCTCATCCGAAACCGCTCTA-3', 5'-GGGGTCTCCTCC TTGCTATCCTG-3'; notch-4: 5'-GCGGAGGCAGGGTCTCAACGGATG-3', 5'-AGG AGGCGGGATCGGAATGT-3'; jagged-1: 5'-CGGGATTTGGTTAATGGTTATC-3', 5'-ATAGTCACTGGCACGGTTGTAGCAC-3'; dII-1: $5^{\prime}$-GGAATGCAAGTGCAGAGT GG-3', 5'-TCTTGCAGGGCTTATGGTGT-3'; E-cadherin : $5^{\prime}$-TGCCCAGAAAATGA AAAAGG-3', 5'-GTGTATGTGGCAATGCGTTC-3'; col1a1: 5'-CCCTGTCTGCTTC CTGTAAACT-3', 5'-CATGTTCGGTTGGTCAAAGATA-3'; actin : 5'-GGACTTCGA GCAAGAGATGG-3', 5'-AGCACTGTGTTGGCGTACAG-3'. For rat; sip1: 5'-TAC GGATCCCGAGACGATAC-3', 5'-CCTCGTGGTCTGATTTGGTT-3'; notch-1: 5'-C TCACGCTGATGTCAATGCT-3', 5'-CGTTCTTCAGGAGCACAACA-3'; jagged-1: 5'-GCGCACTGTGAGAACAACAT-3', 5'-GTTTTCCCTTTCCACCCATT-3'; col1a1:
5'-ATGTCGCTATCCAGCTGACC-3', 5'-TTGAGGTTGCCAGTCTGTTG-3'; e-cadherin: 5'-ATCTCCCTGGAAGCAGGATT-3', 5'-CGGGCTTTGCTGGTGATG-3'; $\alpha$-sma: $5^{\prime}$-GGTCAGGATCCCTCTCTTGCT-3', 5'-CATGTTCGGTTGGTCAAAGAT A-3'; gapdh: 5'-ATGACTCTACCCACGGCAAG-3', 5'-CTGGAAGATGGTGATG GGTT-3'

Immunoblotting analysis. Whole-cell extracts were prepared as described previously. ${ }^{41}$ The protein concentration of the samples was determined using the Bradford method. ${ }^{42}$ Samples were applied to polyacrylamide SDS gels, subjected to electrophoresis, and the resultant proteins immunoblotted with their respective antibodies.

Gelatin zymography. The proteolytic activity of MMP-9 and MMP-2 was assessed by SDS-PAGE using zymogram gels containing $0.1 \%$ gelatin, as described previously. ${ }^{41}$ The FBS-free culture medium was concentrated and protein concentration determined according to the Bradford method. ${ }^{42}$ After electrophoresis at $4^{\circ} \mathrm{C}$, the gels were washed with $2.5 \%$ Triton $\mathrm{X}-100$ for $30 \mathrm{~min}$ at room temperature and incubated with zymogram development buffer for 2 days at $37^{\circ} \mathrm{C}$. Bands were visualized by staining with Coomassie Brilliant Blue.

Cell migration assay. In vitro wound-healing assays were used to assess cell migration as described previously, ${ }^{43}$ using confluent A549 cells on a 24 -well plate. Two linear wounds were scratched with a p200 pipette tip. The cell-free area was measured before and after $24 \mathrm{~h}$ of incubation (healing step) using NIH ImageJ software (NIH, Bethesda, ML, USA).

SiRNA targeting of genes. The siRNAs for DHODH and SIP1 were purchased from Qiagen. A549 cells were transfected with siRNA using HiPerFect transfection reagents according to the manufacturer's instructions. The siRNA $5^{\prime}$-UUCUCCGAACGUGUCACGUDTDT- 3 ' and 5'-ACGUGACACGUUCGGAGAAD TDT-3' was used as a nonspecific siRNA.

Administration of bleomycin, leflunomide and uridine. C57BL/6 mice maintained under chloral hydrate anesthesia $(500 \mathrm{mg} / \mathrm{kg})$ were administered one intratracheal injection of bleomycin $(0.5$ or $5 \mathrm{mg} / \mathrm{kg}$ ) to induce fibrosis. Leflunomide $(40 \mathrm{mg} / \mathrm{kg})$ was dissolved in $1 \%$ methylcellulose and administered orally. Uridine $(50 \mathrm{mg} / \mathrm{kg})$ was dissolved in PBS and administered intratracheally.

Histological and immunohistochemical analyses. Lung tissue samples were fixed in $4 \%$ buffered paraformaldehyde and then embedded in paraffin before being cut into $4-\mu \mathrm{m}$-thick sections.

For histological examination, sections were stained first with Mayer's hematoxylin and then with $1 \%$ eosin alcohol solution. Samples were mounted with malinol and inspected using an Olympus BX51 microscope.

For Masson's trichrome staining of collagen, sections were sequentially treated with solution $\mathrm{A}(5 \%(\mathrm{w} / \mathrm{v})$ potassium dichromate and $5 \%$ (w/v) trichloroacetic acid), Weigert's iron hematoxylin, solution B $(1.25 \%$ (w/v) phosphotungstic acid and $1.25 \%$ (w/v) phosphomolybdic acid), $0.75 \%$ (w/v) Orange G solution, solution C $(0.12 \%(\mathrm{w} / \mathrm{v})$ xylidine ponceau, $0.04 \%(\mathrm{w} / \mathrm{v})$ acid fuchsin and $0.02 \%(\mathrm{w} / \mathrm{v})$ azophloxin), 2.5\% (w/v) phosphotungstic acid, and finally Aniline Blue solution. Samples were mounted with malinol and inspected using an Olympus BX51 microscope.

For immunohistochemical analysis, sections were blocked with $3 \%$ goat serum for $15 \mathrm{~min}$, incubated for $12 \mathrm{~h}$ with antibody against proSP-C and $\alpha$-SMA in the presence of $2.5 \% \mathrm{BSA}$, and finally incubated for $3 \mathrm{~h}$ with Alexa Fluor 488 goat antirabbit lgG and Alexa Fluor 594 goat anti-mouse lgG in the presence of DAPI $(5 \mu \mathrm{g} / \mathrm{ml})$. Samples were mounted with VECTASHIELD and inspected using fluorescence microscopy (Olympus BX51) with deconvolution (Lumina Vision imaging software (Mitani Co., Tokyo, Japan)).

Hydroxyproline determination. Hydroxyproline content was determined as described previously. ${ }^{44}$ Briefly, the right lung was removed and homogenized in $0.5 \mathrm{ml}$ of $5 \% \mathrm{TCA}$. After centrifugation, pellets were hydrolyzed in $0.5 \mathrm{ml}$ of $10 \mathrm{~N} \mathrm{HCl}$ for $16 \mathrm{~h}$ at $110^{\circ} \mathrm{C}$. Each sample was incubated for $20 \mathrm{~min}$ at room temperature after addition of $0.5 \mathrm{ml}$ of $1.4 \%(\mathrm{w} / \mathrm{v})$ chloramine T solution and then incubated at $65^{\circ} \mathrm{C}$ for $10 \mathrm{~min}$ after addition of $0.5 \mathrm{ml}$ of Ehrlich's reagent (1M DMBA, 70\% (v/v) isopropanol and $30 \%$ (v/v) perchloric acid). Absorbance was measured at $550 \mathrm{~nm}$, and the amount of hydroxyproline was determined. 
Statistical analysis. Two-way analysis of variance (ANOVA), followed by Tukey's test or Student's $t$-test for unpaired results was used to evaluate differences between more than three groups or between two groups, respectively. Survival estimates were computed using standard Kaplan-Meier estimates with the log-rank test for the $P$-value of survival curves between BLM-treated mice with and without leflunomide administration. Differences were considered to be significant for values of $P<0.05$.

\section{Conflict of interest}

The authors declare no conflict of interest.

1. Olson AL, Swigris JJ, Lezotte DC, Norris JM, Wilson CG, Brown KK. Mortality from pulmonary fibrosis increased in the United States from 1992 to 2003. Am J Respir Crit Care Med 2007; 176: 277-284.

2. Fumeaux $T$, Rothmeier $C$, Jolliet $P$. Outcome of mechanical ventilation for acute respiratory failure in patients with pulmonary fibrosis. Intensive Care Med 2001; 27: 1868-1874

3. Camus P, Fanton A, Bonniaud P, Camus C, Foucher P. Interstitial lung disease induced by drugs and radiation. Respiration 2004; 71: 301-326.

4. Inoue A, Saijo Y, Maemondo M, Gomi K, Tokue $Y$, Kimura $Y$ et al. Severe acute interstitial pneumonia and gefitinib. Lancet 2003; 361: 137-139.

5. Flieder DB, Travis WD. Pathologic characteristics of drug-induced lung disease. Clin Chest Med 2004; 25: 37-45.

6. Moore BB, Hogaboam CM. Murine models of pulmonary fibrosis. Am J Physiol Lung Cell Mol Physiol 2008; 294: L152-L160

7. Sheppard D. Transforming growth factor beta: a central modulator of pulmonary and airway inflammation and fibrosis. Proc Am Thorac Soc 2006; 3: 413-417.

8. Kinnula VL, Myllarniemi M. Oxidant-antioxidant imbalance as a potential contributo to the progression of human pulmonary fibrosis. Antioxid Redox Signal 2008; 10 $727-738$

9. Hinz B, Phan SH, Thannickal VJ, Galli A, Bochaton-Piallat ML, Gabbiani G. The myofibroblast: one function, multiple origins. Am J Pathol 2007; 170: 1807-1816.

10. Gasse P, Mary C, Guenon I, Noulin N, Charron S, Schnyder-Candrian S et al. IL-1R1/ MyD88 signaling and the inflammasome are essential in pulmonary inflammation and fibrosis in mice. J Clin Invest 2007; 117: 3786-3799.

11. Kisseleva T, Brenner DA. Fibrogenesis of parenchymal organs. Proc Am Thorac Soc 2008; 5: 338-342.

12. Willis $B C, B o r o k Z$. TGF-beta-induced EMT: mechanisms and implications for fibrotic lung disease. Am J Physiol Lung Cell Mol Physiol 2007; 293: L525-L534.

13. Kasai H, Allen JT, Mason RM, Kamimura T, Zhang Z. TGF-beta1 induces human alveolar epithelial to mesenchymal cell transition (EMT). Respir Res 2005; 6: 56.

14. Kim KK, Kugler MC, Wolters PJ, Robillard L, Galvez MG, Brumwell AN et al. Alveola epithelial cell mesenchymal transition develops in vivo during pulmonary fibrosis and is regulated by the extracellular matrix. Proc Natl Acad Sci USA 2006; 103: 13180-13185.

15. Kim KK, Wei Y, Szekeres C, Kugler MC, Wolters PJ, Hill ML et al. Epithelial cell alpha3beta1 integrin links beta-catenin and Smad signaling to promote myofibroblast formation and pulmonary fibrosis. J Clin Invest 2009; 119: 213-224.

16. Smolen JS, Kalden JR, Scott DL, Rozman B, Kvien TK, Larsen A et al. Efficacy and safety of leflunomide compared with placebo and sulphasalazine in active rheumatoid arthritis: double-blind, randomised, multicentre trial. European Leflunomide Study Group. Lancet 1999; 353: 259-266.

17. Emery P, Breedveld FC, Lemmel EM, Kaltwasser JP, Dawes PT, Gomor B et al. A comparison of the efficacy and safety of leflunomide and methotrexate for the treatment of rheumatoid arthritis. Rheumatology (Oxford) 2000; 39: 655-665.

18. Fox RI, Herrmann ML, Frangou CG, Wahl GM, Morris RE, Strand V et al. Mechanism of action for leflunomide in rheumatoid arthritis. Clin Immunol 1999; 93: 198-208.

19. Scott DL. Interstitial lung disease and disease modifying anti-rheumatic drugs. Lancet 2004: 363: 1239-1240.

20. Sakai F, Noma S, Kurihara Y, Yamada H, Azuma A, Kudoh S et al. Leflunomide-related lung injury in patients with rheumatoid arthritis: imaging features. Mod Rheumatol 2005; 15 173-179.
21. Mejlvang J, Kriajevska M, Vandewalle C, Chernova T, Sayan AE, Berx G et al. Direct repression of cyclin D1 by SIP1 attenuates cell cycle progression in cells undergoing an epithelial mesenchymal transition. Mol Biol Cell 2007; 18: 4615-4624.

22. Thiery JP, Sleeman JP. Complex networks orchestrate epithelial-mesenchymal transitions. Nat Rev Mol Cell Biol 2006; 7: 131-142.

23. Shirakihara T, Saitoh M. Miyazono K. Differential regulation of epithelial and mesenchyma markers by deltaEF1 proteins in epithelial mesenchymal transition induced by TGF-beta. Mol Biol Cell 2007; 18: 3533-3544.

24. Saito RA, Watabe T, Horiguchi $K$, Kohyama $T$, Saitoh M, Nagase $T$ et al. Thyroid transcription factor-1 inhibits transforming growth factor-beta-mediated epithelial-tomesenchymal transition in lung adenocarcinoma cells. Cancer Res 2009; 69: 2783-2791.

25. Li JL, Harris AL. Notch signaling from tumor cells: a new mechanism of angiogenesis. Cancer Cell 2005; 8: 1-3.

26. Bray SJ. Notch signalling: a simple pathway becomes complex. Nat Rev Mol Cell Biol 2006; 7: 678-689.

27. Sahlgren C, Gustafsson MV, Jin S, Poellinger L, Lendahl U. Notch signaling mediates hypoxia-induced tumor cell migration and invasion. Proc Natl Acad Sci USA 2008; 105: 6392-6397.

28. Wang Z, Li Y, Kong D, Banerjee S, Ahmad A, Azmi AS et al. Acquisition of epithelialmesenchymal transition phenotype of gemcitabine-resistant pancreatic cancer cells is linked with activation of the notch signaling pathway. Cancer Res 2009; 69: 2400-2407.

29. Kuo EA, Hambleton PT, Kay DP, Evans PL, Matharu SS, Little E et al. Synthesis, structureactivity relationships, and pharmacokinetic properties of dihydroorotate dehydrogenase inhibitors: 2-cyano-3-cyclopropyl-3-hydroxy-N-[3'-methyl-4'-(trifluoromethyl)phenyl] propenamide and related compounds. J Med Chem 1996; 39: 4608-4621.

30. Hatse S, De Clercq E, Balzarini J. Role of antimetabolites of purine and pyrimidine nucleotide metabolism in tumor cell differentiation. Biochem Pharmacol 1999; 58: 539-555.

31. Yukawa E, Mori S, Ueda K, Nakada Y. Population pharmacokinetic investigation of low-dose methotrexate in rheumatoid arthritics Japanese patients. J Clin Pharm Ther 2007; 32: 573-578.

32. Chan V. Charles BG, Tett SE. Population pharmacokinetics and association between A77 1726 plasma concentrations and disease activity measures following administration of leflunomide to people with rheumatoid arthritis. Br J Clin Pharmacol 2005; 60: 257-264.

33. Baumann P, Mandl-Weber S, Volkl A, Adam C, Bumeder I, Oduncu F et al. Dihydroorotate dehydrogenase inhibitor A771726 (leflunomide) induces apoptosis and diminishes proliferation of multiple myeloma cells. Mol Cancer Ther 2009; 8: 366-375.

34. Tang X, Yang J, Li J. Accelerative effect of leflunomide on recovery from hepatic fibrosis involves TRAlL-mediated hepatic stellate cell apoptosis. Life Sci 2009; 84: 552-557.

35. Liu T, Hu B, Choi YY, Chung M, Ullenbruch M, Yu H et al. Notch1 signaling in FIZZ1 induction of myofibroblast differentiation. Am J Pathol 2009; 174: 1745-1755.

36. Hamilton LC, Vojnovic I, Warner TD. A771726, the active metabolite of leflunomide, directly inhibits the activity of cyclo-oxygenase-2 in vitro and in vivo in a substrate-sensitive manner. Br J Pharmacol 1999; 127: 1589-1596.

37. Xu X, Williams JW, Bremer EG, Finnegan A, Chong AS. Inhibition of protein tyrosine phosphorylation in T cells by a novel immunosuppressive agent, leflunomide. J Biol Chem 1995; 270: 12398-12403.

38. Inokuma S, Sato T, Sagawa A, Matsuda T, Takemura T, Ohtsuka T et al. Proposals for leflunomide use to avoid lung injury in patients with rheumatoid arthritis. Mod Rheumatol 2008; 18: 442-446.

39. Isohama Y, Kanemaru M, Kai H, Takahama K, Miyata T. Interaction between betaadrenergic signaling and protein kinase $\mathrm{C}$ increases cytoplasmic $\mathrm{Ca} 2+$ in alveolar type II cells. Life Sci 2001; 68: 2361-2371.

40. Isohama Y, Matsuo T, Kai H, Takahama K, Miyata T. Changes in beta 1- and beta 2-adrenoceptor mRNA levels in alveolar type II cells during cultivation. Biochem Mol Biol Int 1995; 36: 561-568.

41. Namba T, Homan T, Nishimura T, Mima S, Hoshino T, Mizushima T. Up-regulation of S100P expression by non-steroidal anti-inflammatory drugs and its role in anti-tumorigenic effects. J Biol Chem 2009; 284: 4158-4167.

42. Bradford MM. A rapid and sensitive method for the quantitation of microgram quantities of protein utilizing the principle of protein-dye binding. Anal Biochem 1976; 72: 248-254.

43. Mima S, Tsutsumi S, Ushijima H, Takeda M, Fukuda I, Yokomizo K et al. Induction of claudin-4 by nonsteroidal anti-inflammatory drugs and its contribution to their chemopreventive effect. Cancer Res 2005; 65: 1868-1876.

44. Woessner $\mathrm{Jr} \mathrm{JF}$. The determination of hydroxyproline in tissue and protein samples containing small proportions of this imino acid. Arch Biochem Biophys 1961; 93: 440-447.

\section{Supplementary Information accompanies the paper on Cell Death and Differentiation website (http://www.nature.com/cdd)}

